
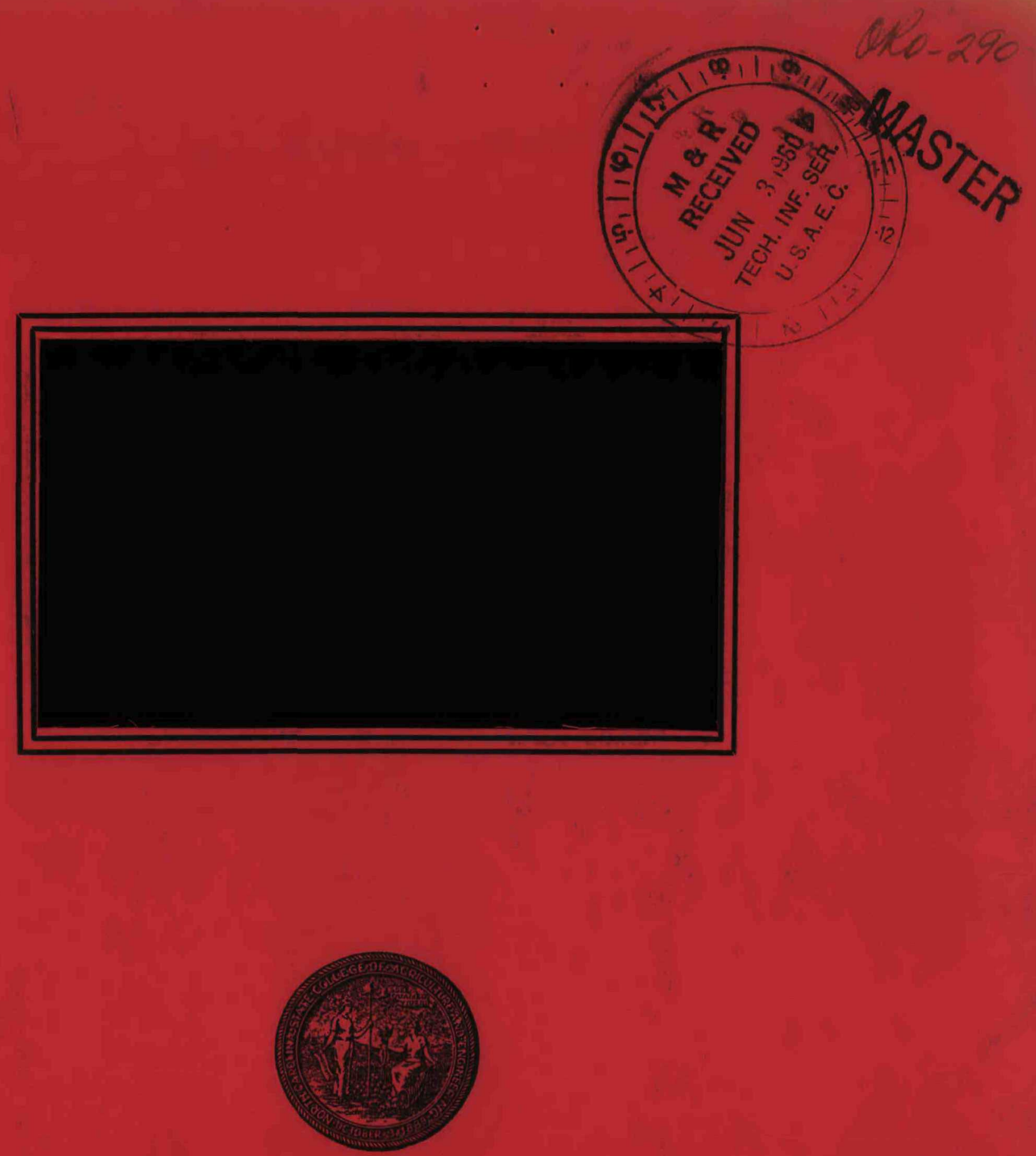

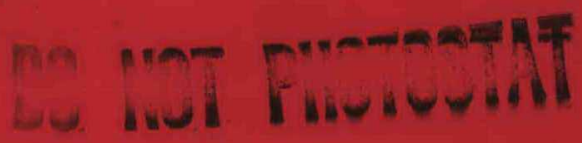

DEPARTMENT OF ENGINEERING RESEARCH NORTH CAROLINA STATE COLIEGE

RALEIGH, NORTH CAROLINA 


\section{DISCLAIMER}

This report was prepared as an account of work sponsored by an agency of the United States Government. Neither the United States Government nor any agency Thereof, nor any of their employees, makes any warranty, express or implied, or assumes any legal liability or responsibility for the accuracy, completeness, or usefulness of any information, apparatus, product, or process disclosed, or represents that its use would not infringe privately owned rights. Reference herein to any specific commercial product, process, or service by trade name, trademark, manufacturer, or otherwise does not necessarily constitute or imply its endorsement, recommendation, or favoring by the United States Government or any agency thereof. The views and opinions of authors expressed herein do not necessarily state or reflect those of the United States Government or any agency thereof. 


\section{DISCLAIMER}

Portions of this document may be illegible in electronic image products. Images are produced from the best available original document. 


\title{
ORO -290
}

\author{
PROGRESS REPORT NO. 13 \\ covering the specific topic of \\ THE DEVELOPMENT OF A PULSE-COLUMN \\ SAMPLING TECHNIQUE TO OVERCOME \\ ENTRA INMENT \\ Contract AT- $(40-1)-1320$ \\ The Performance of Contactors for \\ Liquid-Liquid Extraction
}

Topic Personnel:

W. F. Boerner

E. E. Erickson

F. O. Mixon, Jr.

J. R. Ne11i

F. P. Pike
Submitted by:

$$
\begin{aligned}
& \text { F. Philips Pike } \\
& \text { Project Director } \\
& \text { Professor of Chemical } \\
& \text { Engineering }
\end{aligned}
$$

DEPARTMENT OF ENGINEERING RESEARCH NORTH CAROLINA STATE COLLEGE

RALEIGH, NORTH CAROLINA

April 26, 1955 
THE DEVELOPMENT OF A PULSE-COLUMN SAMPLING

TECHNIQUE TO OVERCOME ENTRA INMENT

TABLE OF CONTENTS

Page

Table Index

Figure Index

$\begin{array}{ll}\text { Summary } & 1\end{array}$

Statement of the Problem 3

Introduction $\quad 4$

$\begin{array}{ll}\text { Preliminary Experiments } & 7\end{array}$

$\begin{array}{ll}\text { Introduction } & 7\end{array}$

$\begin{array}{ll}\text { Apparatus } & 8\end{array}$

Filter Media $\quad 8$

$\begin{array}{ll}\text { Procedures } & 13\end{array}$

Results $\quad 14$

Conclusions $\quad 20$

Preliminary Column Test 21

Column Installation of Filter Units 25

Information from Recent Paper 29

Appendix

A. Nomenclature 33

B. Discussion of Equation for Pressure Drop 34

C. Sample Calculations 36

D. Pressure-Drop and Flow-Rate Data 40

E. Haze Characterization and Setting Rate Studies 47

F. Cleaning Procedures for Tubular 51 Fritted-Glass Filters 


\section{TABLE INDEX}

Table

Page

I Pertinent Physical Information for Various Filter Media.

II Filter Constants.

II Pressure-drop and Flow-rate Data for Water Flowing thru Simulated Filter-tube Neck and External Fittings.

IV Data for the Filtration of Distilled Water with a 4-inch Coarse-porosity Filter.

$v$ Data for the Filtration of Distilied Water with a 4-inch Medium-porosity Filter.

VI Data for the Filtration of Distilled Water with a 2-inch Coarse-porosity Filter.

VII Data for the Filtration of Benzene with a 4-inch Coarse-porosity Filter.

VIII Data for the Filtration of Benzene with a 4-inch Medium-porosity Filter.

IX Data for the Filtration of Benzene with a 2-inch Coarse-porosity Filter.

$X$ Comparison of Various Hazes by Means of Light Absorption.

XI Measurement of Settling-rates of Benzenewater Dispersions. 
FIGURE INDEX

Figure

Page

1 Schematic Diagram of Preliminary Filter Testing Apparatus.

2 Preliminary Filter Testing Apparatus.

3 Filter Chamber.

4 Fritted Pyrex Tubular Filters.

5 Pressure-drop and Flow-rate Behavior for Water and Benzene Flowing thru Neck and External Fittings of Filter Thimbles.

$15 a$

6 Flow Characteristics of 4-inch Coarse Filters. 17

7 Flow Characteristics of 4-inch Medium Filters. 18

8 Flow Characteristics of 2-inch Coarse Filters. 19

$9 \quad$ Details of Column Filtering Apparatus. 22

$10 \quad$ Column Filtering Unit. 23

11 Schematic Diagram of Column with Temporary Filtering Units Installed.

12 Filter Installation at Top of Column. 26

13 Filter Installation at Bottom of Column. 27

14 Details of Filter Fitting. 28

15 Viscosity of Water. $\quad 38$

16 Viscosity of Benzene. $\quad 39$

17 Settling Rates of Water-in-benzene and Benzene-in-water Dispersions. 


\section{THE DEVELOPMENT OF A PULSE-COLUMN SAMPLING TECHNIQUE TO OVERCOME ENTRAINMENT}

Eugene E。 Erickson, Forest O. Mixon, Jr.,
and F。 Philips Pike

\section{SUMMARY}

An adequate solution has been found to the problem of obtaining a clear, homogeneous sample of the continuous phase of the unstable dispersions which are characteristic of pulse column exit streams. While for many purposes these dispersions cause little trouble, experience had indicated that even a trace of a second phase can absolutely ruin an analysis when the attempt is being made, with relatively insoluble liquids, to measure individual-film mass-transfer coefficients. Therefore, for the purposes of this project, a solution to this apparently minor problem was mandatory.

A preliminary investigation revealed that frittedglass tubular filters adequately removed the dispersed material from either phase, even when the emulsions were more finely divided than those produced by the pulse column. Pressuredrop studies proved these filters to be practical for the low flow-rates of the sampling lines. Temporary filter units, installed on the pulse-column and tested under operating conditions, gave added assurance that the fritted glass filters would accomplish the desired purpose.

The information gained was utilized in designing effluent sampling sections, containing the fritted-glass tubular 
filters, for the column discharge lines. The units were constructed, installed and tested and have provided a satisfactory solution to the entrainment problem.

The pressure-drop across the filter-tube at sampling flowrates was compared with that pressure that will rupture the Interface at the capillary entrance of a preferentially wetted membrane, as developed by Jordan* in a recent paper. Data for the separation of entrainment in the water phase indicate the pressure-drops to be well under Jordan's rupture pressure. The fact that the filter, which would be wetted preferentially by water, appears to operate satisfactorily also in the benzene phase lends support to an originally assumed analogy to the filtration of small particles suspended in a liquid.

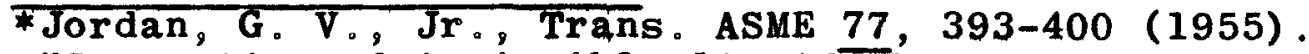
"Separation of Immiscible liquids by means of porous membranes."
} 
STATEMENT OF THE PROBLEM

The purpose of this work was to develop, install and demonstrate a means for completely separating enough of the continuous phase for analysis of the various benzene-inwater and water-in-benzene dispersians which form the exit streams from the pulse column. Such a means was absolutely necessary in order to permit studies of rate of mass transfer between the phases, to obtain individual-film mass-transfer coefficients. 


\section{INTRODUCTION}

Pulse column operation, because of its forceful back and forth surges thru the plate perforations, is prone to develop unstable emulsions of the two liquid streams present. The column end-sections, almost invariably larger in diameter than the column proper, serve to some degfee to settle out the coarser components of these dispersions in the exit streams. Yet each of the exit phases tends to contain a fine dispersion of the other phase.

Inspection of column operation reveals that at times this emulsion formation is much worse than at others. Some conditions of pulse frequency, pulse ampl 1 tude and flow-rates permit almost clear exit streams; some, on the other hand, cause dispersions of droplets so fine and so numerous as to be milky in appearance. It might be presumed that this trouble would affect only the continuous phase, since the pulse column action is designed specifically to be always dispersing the discontinuous phase. However, both exit streams exhibit this phenomenon.

These emulsions of the exit streams are very troublesome in many cases. In the present work, where the measurement of individual-film mass-transfer coefficients is a goal, the presence of even a trace of dispersion makes it impossible to carry out the necessary analytical measurements. This is so because the two phases being employed, benzene and water, are practically insoluble in each other. For instance, at saturation around room temperature, benzene dissolves only 
about 0.060 weight percent water. Since the exit stream analysis normally is over 90 percent of saturation, it is obvious that even a trace of droplet contamination, say 0.006 weight percent, would cause serious error. The result is that the samples taken for analysis of the exit streams must be deentrained completely and without question.

The problem as stated above may seem strange, since it is common practice in pulse column work to ignore the emulsion situation (except in fegard to decontamination). The samples are merely set aside long enough for complete separation to take place, then analyzed. However, in all of those cases the interest lies in a third component, whose distribution is rarely changed apprectably by the haze present, Only when one is interested in the mutual degree of saturation of the two liquid phases, the present case, does the problem become severe.

For a number of reasons it appeared best to plan not to de-entrain the entire exit stream, but rather to clarify only that portion sampled for analysis. Every device or means considered added to the time of contact provided by the pulse column, and therefore caused added mass-transfer to take place. This disadyantage had to be accepted. The additional mass-transfer effect would then be merely added to that already known to exist for the column onds, as distinct from the pulse column proper. However, to minimize this additional end-effect, the separating means should be small and installed as close as possible to the column. 
The unit operation of filtration appeared to be the simplest available means of carrying out the desired separation. This preliminary selection raised questions of the separating ability of various filtration media, their pressure drop, wettability, size, shape, and ease of installation and replacement. Glass members were favored, although finely woven wire screen seemed a possibility. 


\section{PRELIMINARY EXPERIMENTS}

\section{Introduction}

The preliminary experiments were made to test filtration as a means of clarification, and to provide quantitative information on the performance of various filter media. These experiments fell into three classes, as follows.

1. Experiments concerning the ability of various media to clarify emulsions of water and benzene. This was done by filtering fine dispersions of water in benzene and benzene in water thru various filter media, and observing the nature of the filtrate.

2. Experiments concerning pressure drop and flow rate behavior. For this phase, pure benzene and pure water were forced thru the filters at measured rates under measured pressures. At the time these measurements were made, one idea was to install the filtering unit inside the column endsection and to filter the entire exit stream. Such a procedure made pressure drop measurements necessary. An advantage to this method would have presumably been a reduction of the mass transfer end-effect. Later, it was decided to filter only the portion sampled. In that case, the pressure drop data became desirable but not necessary.

3. Miscellaneous experiments to test clogging and plugging tendencies, and the cleaning procedures required for tubular fritted-glass filter units. 


\section{Apparatus}

The equipment used for the preliminary testing of fritted-glass filter units consisted mainly of standard laboratory glassware. The laboratory air supply was first filtered, to remove solid or liquid particles that might tend to clog the filter units being tested. This filtered air then pressurized a solution chamber containing the liquid phases to be tested, forcing one of them through/unit which was installed Inside a glass tee. By sultably raising or lowering the outlet tube from the solution chamber, either of the two phases could be forced out. Auxiliary openings on the glass tee permitted measurements of temperature and pressure. The arrangment of apparatus is shown schematically in Figure 1. A photograph of the entire assembly, an enlarged view of the filter-chamber and a photograph of two of the filter-tubes may be seen in Figure 2,3 and 4 respectively.

When wire screening was tested, a plece of 2-inch Pyrex pipe, 5 inches long, was attached to the discharge end of the tee (see Figure 1) with a flange assembly employing two Ameripole rubber gaskets. The sample of metal screen was sandwiched between the two gaskets.

\section{Filter Media}

The filter media evaluated are listed in Table 1 . They consisted of Pyrex fritted-glass tubular units and metal toel screening of close weaves. 


\section{SCHEMATIC DIAGRAM OF PRELIMINARY FILTER \\ TESTING APPARATUS}

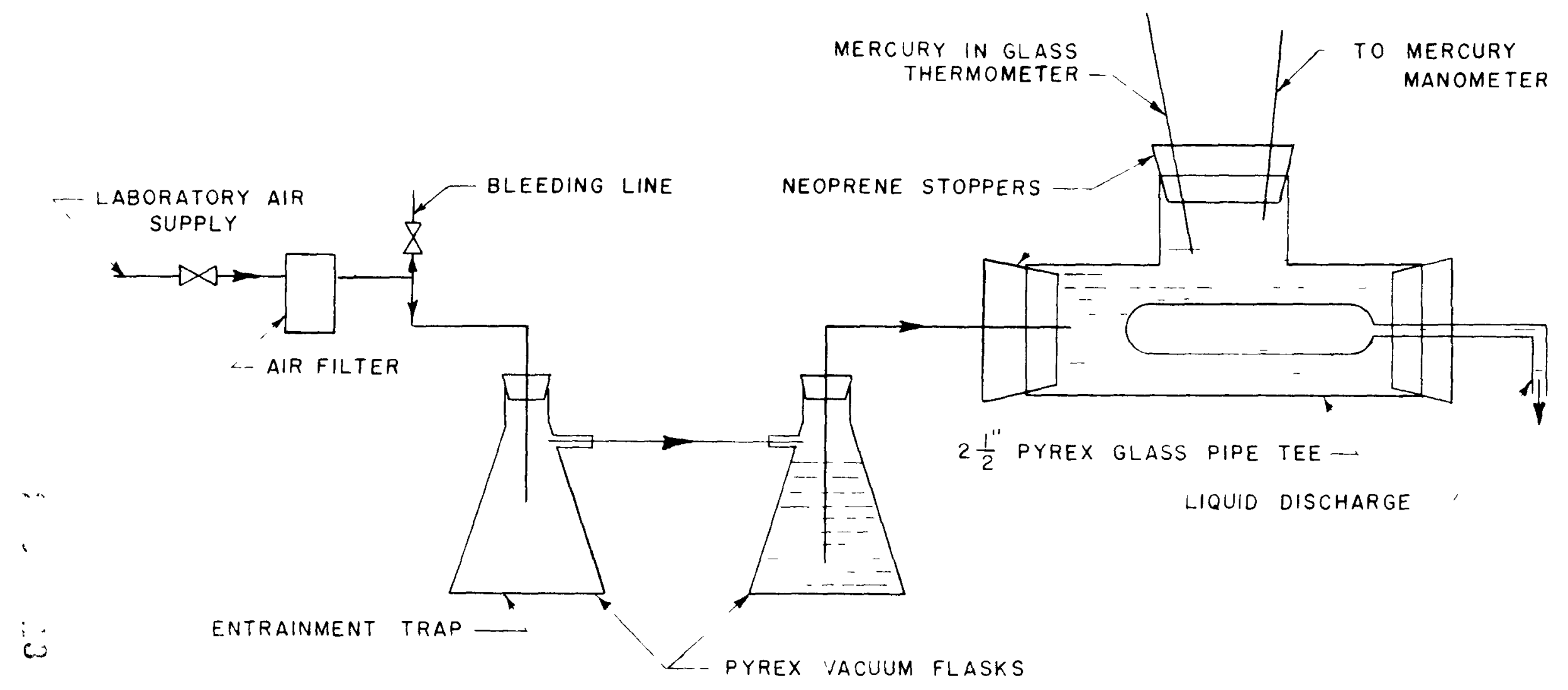




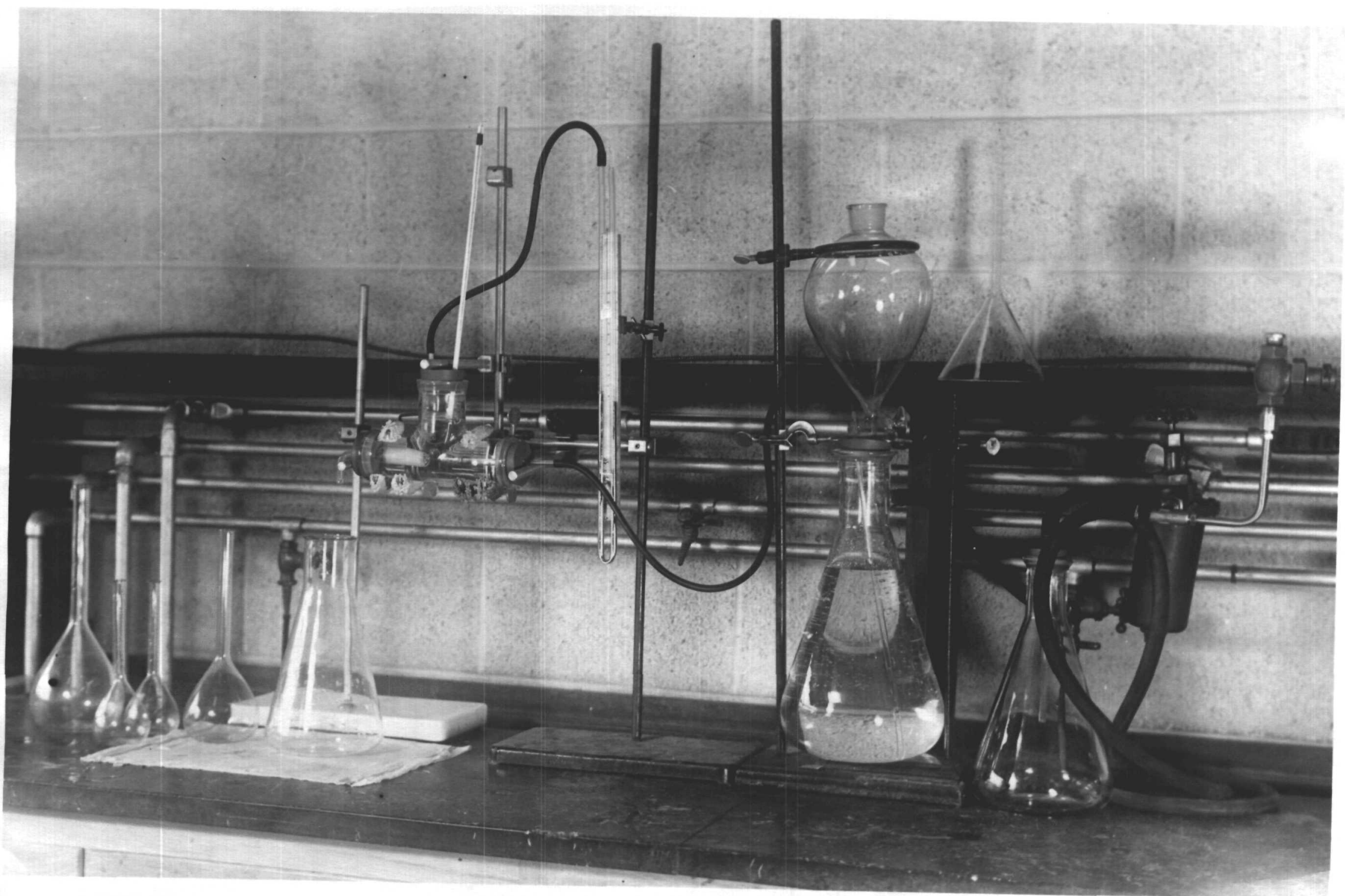

FIGURE 2

PRELIMINARY FILTER TESTING APPARATUS 

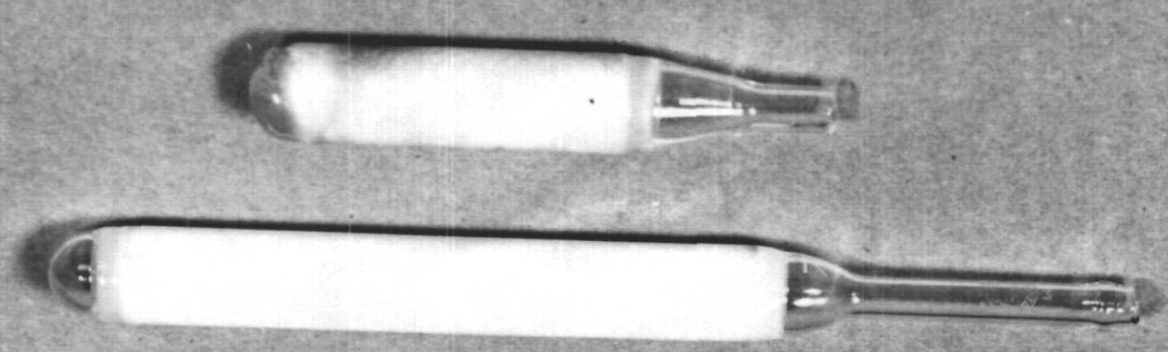

FRITTED PYREX TUBULAR FILTERS

FIGJRE 4 


\section{TABLE I}

Pertinent Physical Information for Various Filter Media

\begin{tabular}{|c|c|c|c|c|c|c|}
\hline Filter & $\begin{array}{l}\text { Material } \\
\text { of Con- } \\
\text { struction }\end{array}$ & Mesh & $\begin{array}{c}\text { Approxi- } \\
\text { mate } \\
\text { Pore } \\
\text { Size } \\
\text { Microns }\end{array}$ & $\begin{array}{l}\text { Out- } \\
\text { side } \\
\text { Diam. } \\
\text { in. }\end{array}$ & $\begin{array}{l}\text { Leng th } \\
\text { in. }\end{array}$ & $\begin{array}{l}\text { Filter- } \\
\text { ing Area } \\
\text { in. } 2\end{array}$ \\
\hline Screen & $\begin{array}{l}\text { Phosphor- } \\
\text { bronze }\end{array}$ & $200 \times 200$ & & & & \\
\hline Screen & $\begin{array}{c}\text { Brass } \\
\text { wire }\end{array}$ & $100 \times 100$ & & & & \\
\hline Screen & $\begin{array}{c}\text { Stainless } \\
\text { steel }\end{array}$ & $100 \times 100$ & & & & \\
\hline Screen & $\begin{array}{l}\text { Stainless } \\
\text { steel }\end{array}$ & $700 \times 60$ & & & & $\checkmark$ \\
\hline $\begin{array}{l}\text { Tubular* } \\
\text { filters }\end{array}$ & $\begin{array}{l}\text { Fritted } \\
\text { glass }\end{array}$ & Coarse & $40-60$ & 0.615 & 3.969 & 7.620 \\
\hline$"$ & $"$ & & $40-60$ & 0.606 & 3.969 & 7.556 \\
\hline$"$ & $"$ & $"$ & $40-60$ & 0.630 & 1.844 & 3.650 \\
\hline$"$ & $"$ & $"$ & $40-60$ & 0.632 & 1.969 & 3.910 \\
\hline$"$ & $"$ & Medium & $10-15$ & 0.598 & 3.906 & 7.341 \\
\hline$"$ & $"$ & $"$ & $10-15$ & 0.605 & 3.938 & 7.485 \\
\hline
\end{tabular}

*Corning tubular fritted-glass fitters, Catalog No. 35,000 .

\section{Procedures}

It was not practical to obtain the liquid-liquid dispersions for testing from the pulse column unit. Futhermore, these dispersions were not stable enough for testing. Much more stable emulsions were manufactured by heating mixtures of benzene and water to about $65^{\circ} \mathrm{C}$, agitating vigorously for a short time to approach saturation in both phases, then cooling to room temperature. This procedure yielded very fine 
dispersions, or mists, that appeared to be finer than those obtained under even the worst conditions of pulse column operation. A description of the trials that led to standardization of the procedure for manufacturing the test haze is given in the Appendix .

The various filter media were tested for their ability to produce a clear filtrate from the hazy test solutions. The criterion was the visible appearance of the filtrate, and the relative lack of droplets.

The procedure for obtaining flow-rate and pressuredrop data was quite similar. The (pressure) flask was charged with the liquid to be tested, and the pressurizing air was adjusted to give a predetermined pressure drop across the filtering device; after a brief period to assure steady-state operation, the rate of discharge from the filtering chamber was measured by timing the flow into a volumetric flask of appropriate size. A separate set of measurements were made to determine the pressure drop due to external connections to the filter unit.

\section{$\underline{\text { Results }}$}

The results are summarized here. Most of the supporting information is placed in the Appendix.

1. Evaluation of Various Filter Media. All of the woven-wire filter clothes were found to be unsatisfactory for the filtration of both the benzene phase and the water phase dispersions. These woven clothes included the tightest weaves available on the market. 
It is significant that the $700 \times 60$ mesh dutch twill cloth had previously been found to be fairly effective on actual pulse column dispersions. The fact that it was completely ineffective on the test dispersions indicated that the adopted test procedure was a relatively severe test. In other words, the haze emulsion must have been much finer than the pulse column emulsions, as indeed they so appeared by eye.

It was found that the fritted-glass filter units separated the dispersions rather effectively. For the benzenein-water dispersions, both the coarse and medium grade filters were perfectly satisfactory. For the water-in-benzene dispersions, the coarse grade units were not always completely satisfactory. They did effect a marked reduction in the number of droplets but still let some material thru.

2. Pressure Drop and Flow Information. It was found that the pressure drop across a filter unit can be considered to be made up of two component parts, the pressure drop across the fritted section and the pressure drop due to the glass neck and outlet tube. In order to separate these two components, a small glass tee was made up to approximately the dimensions of the neck of the tubular filter. The pressure drop was then measured across this unit as a function of flow rate. The results are plotted on Figure 5, where the actual data points were obtained using water as the fluid. The dashed line for benzene was obtained by calculation, assuming that $\Delta \mathrm{P}_{\text {Benzene }}=\Delta \mathrm{P}_{\mathrm{H}_{2}} \mathrm{O}\left(\frac{\rho_{\mathrm{B}}}{\rho_{\mathrm{W}}}\right)$, which is approximately correct. These $\Delta P$ values were used to correct the observed $\Delta P$ to provide only the $\Delta P$ across the filtering section. 
PRESSURE DROP AND FLOW RATE BEHAVIOR FOR WATER AND BENZENE FLOWING THROUGH NECK AND EXTERNAL FITTINGS OF FILTER THIMBLES

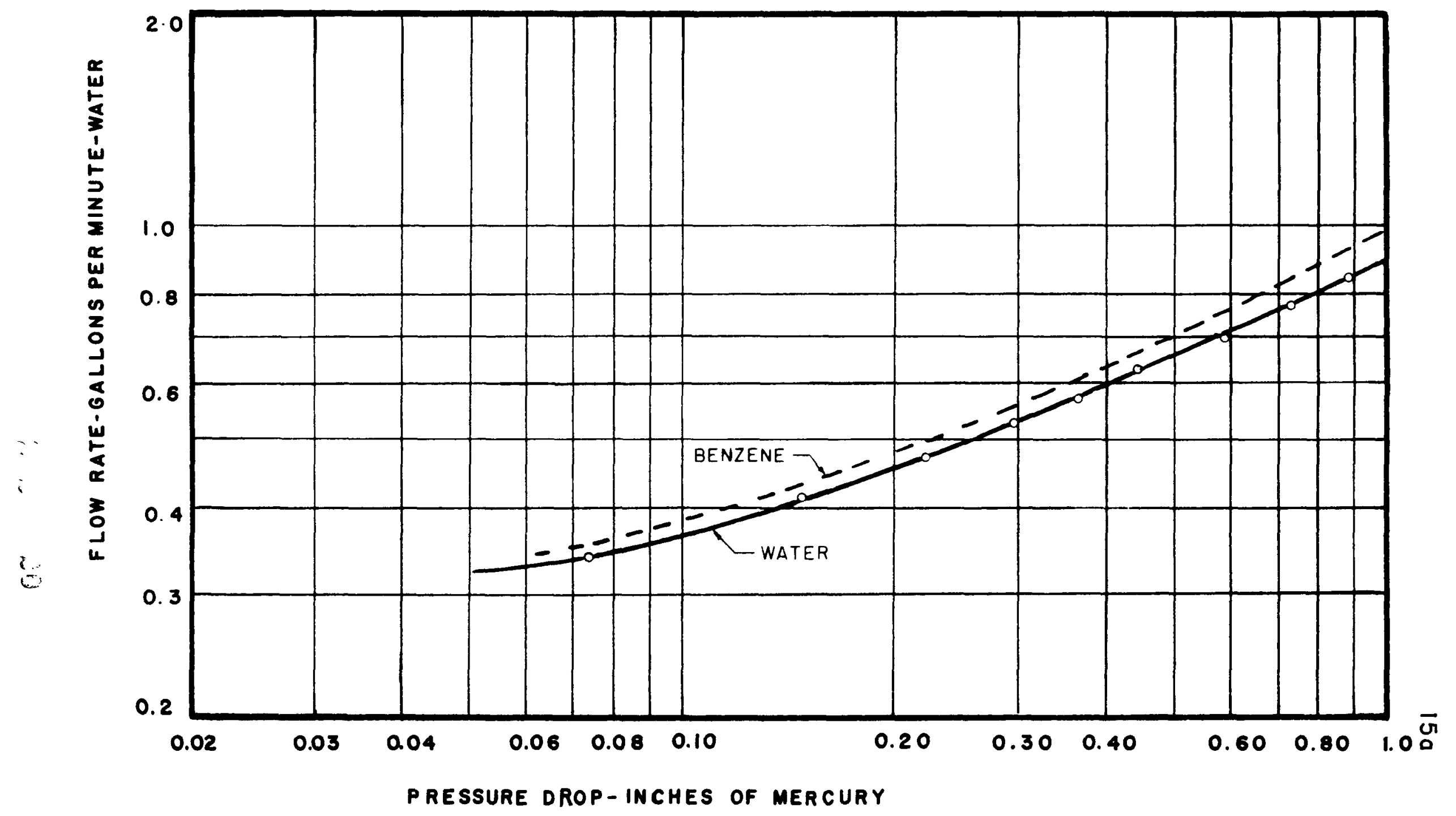


For the flow thru the fritted-glass section, it was assumed that the ordinary filtration equation, based upon Poiseullle's law, was applicable. The form used was as follows.

$$
\begin{aligned}
\frac{\mu v}{A \theta} & =K \frac{\pi D^{4} g}{128 L} \Delta P \\
\left(\frac{\mu}{A}\right) q & =K \cdot \Delta P, \text { where } q=\left(\frac{v}{\theta}\right)
\end{aligned}
$$

See the Appendix for the nomenclature.

The value of $K^{\prime}$ is characteristic of the grade of fritted giass. It was determined as the slope of a plot of $\frac{\mu V}{\mathrm{A \theta}}$ vS. $\Delta \mathrm{P}$, where the $\Delta \mathrm{P}$ has been corrected for the pressure drop in the extraneous connections. Plots of this type are shown in Figures 6,7 and 8 . A dashed line is used to indicate the total $\Delta \mathrm{P}$ as measured, where the above corrections are appreciable. The properly corrected values were used to determine the values of the constant $K$ ' for various filters, which are tabulated in Table II, As $K$ ' characterizes a given filter, once it has been determined, the pressure-drop through the porous media at any given flow-rate can be found quite readily. The $\Delta P$ for the external fittings can be estimated from Figure 5 .

\begin{tabular}{|c|c|c|c|}
\hline $\begin{array}{l}\text { Filter } \\
\text { esignation }\end{array}$ & $\begin{array}{c}\text { Length of } \\
\text { Fretted Section } \\
\end{array}$ & $\begin{array}{c}\text { Stated } \\
\text { Porosity } \\
\end{array}$ & $\frac{\frac{\text { Value af }}{(\mathrm{Cp})(\mathrm{sec}}}{(\mathrm{in} \cdot 2)(\mathrm{min})(\mathrm{i}}$ \\
\hline $\begin{array}{l}4-C-1 \\
4-C-2 \\
4-M-1 \\
4-M-2 \\
2-C-1 \\
2-C-2\end{array}$ & $\begin{array}{l}4 \text { in. } \\
4 \text { in. } \\
4 \text { in. } \\
4 \text { in. } \\
2 \text { in. } \\
2 \text { in. }\end{array}$ & $\begin{array}{l}\text { Coarse } \\
\text { Coarse } \\
\text { Medium } \\
\text { Medium } \\
\text { Coarse } \\
\text { Coarse }\end{array}$ & $\begin{array}{l}0.0400 \\
0.0500 \\
0.0048 \\
0.0014 \\
0.0156 \\
0.0360\end{array}$ \\
\hline
\end{tabular}

\section{TABLE II}


FIGURE 6

FLOW CHARACTERISTICS OF FOUR-INCH, COARSE FILTERS

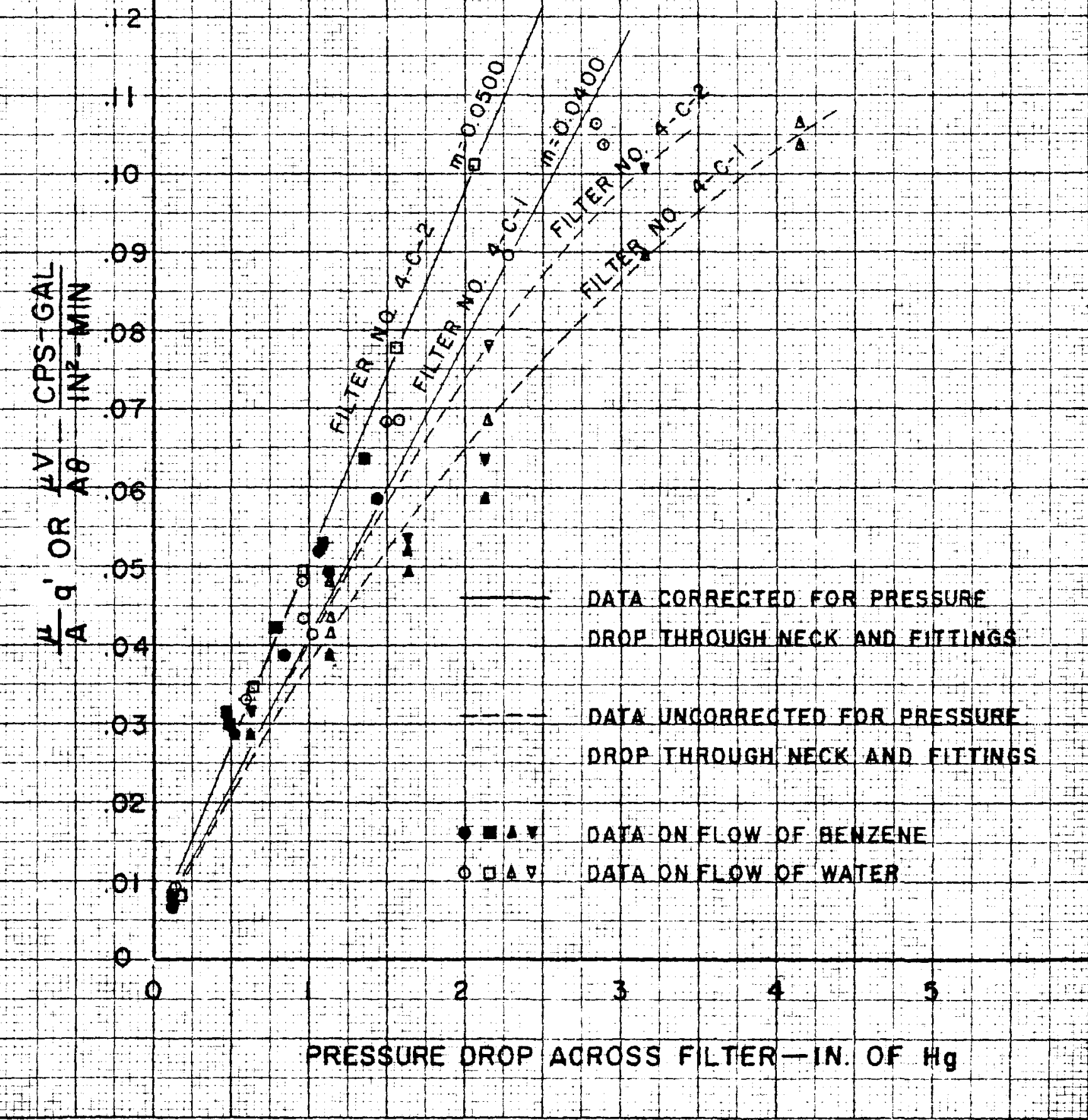


FIGURE 7

FLOW CHARACTERISTICS OF EOUR-INCH MEDIUM FILTERS

CORRECTIONS FOR PRESSURE DROP THROUGH NECK ANO FITINGS ARE NEGLIGIBLE

Q_D PATA QN ELOW OE WATER

- pata pn elow of benzene

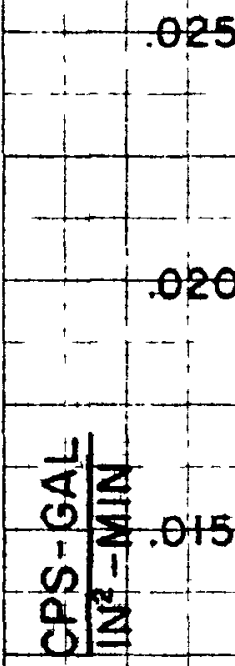

700

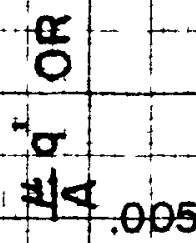

b

0. 2 2 3

PRESSURE QROP ACROSS EIIITER IIN QF Hg 
FIGURE 8

FLOW CHARACTERISTICS OF TWO-INCH COARSE FILTERS

.14

13

12

J

.09

$+1$

की

012.07

10

10

.08

$-1-1$

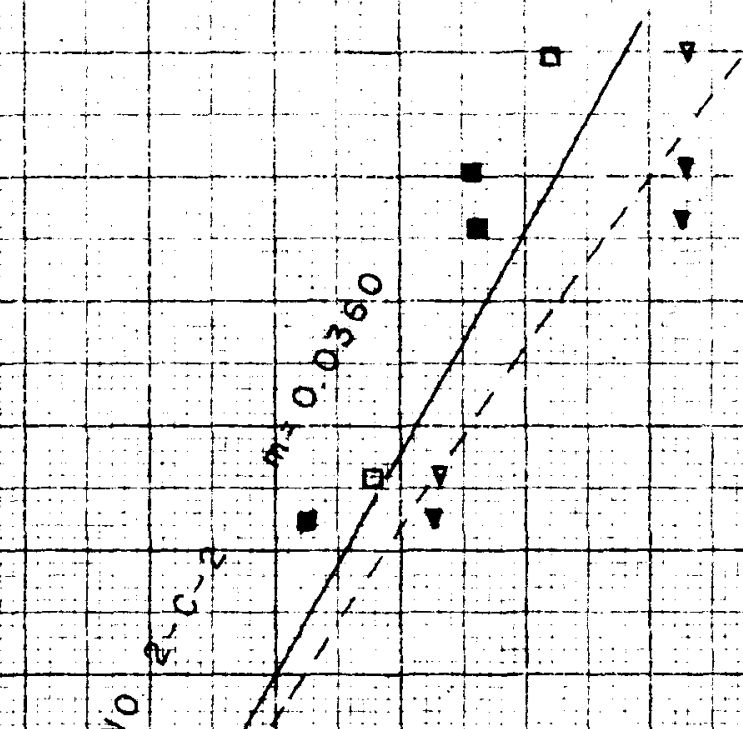

o $\quad 05$
$0 \quad 0.04$

.03

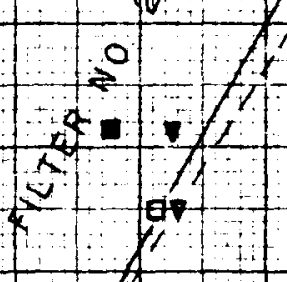


If the entire exit stream flow is to be filtered, both of the pressure drop components are significant. However, if only the sample portion is to be flltered, the pressure drop for the neck section can be ignored.

3. General Observations. It was noted that under some conditions the filter units could become clogged. When an attempt was made to filter tap water, rather than distilled water, a coarse filter unit became badly plugged after the passage of only about $500 \mathrm{ml}$, of liquid. However, when distilled water was used, there was no noticeable decrease in flow rate, at constant pressure, after filtering as much as 5 liters of liquid.

It was found that the filter units could be cleaned and unclogged by following the cleaning procedure recommended by the manufacturer. Procedures suitable for cleaning are presented in the Appendix.

\section{Conclusions}

It was concluded that fritted-glass tubular filter units would probably be satisfactory in filtering ability, flow capacity, size, shape and ease of cleaning.

The various wire clothes, even the most tightly woven ones obtainable, did not possess the ability to clarify properly the test hazes.

The procedure for evaluating the filter media employed dispersions more difficult to clarify than those encountered in pulse column operations. 


\section{PRELIMINARY COLUMN TEST}

While material for a permanent installation was being acquired, a preliminary column test was made to check the conclusion that fritted-glass filter units were suitable means of de-entraining the samples from the pulse column. Temporary units were constructed simply of brass, Ameripole rubber and stainless steel, A drawing of the temporary filtering unit is shown in Figure 9, and a photograph in Figure 10. A schematic diagram of the installed positions is shown in Figure 11 .

After installation the pulse column was set into operation at the following conditions, which were known to and did cause quite distinct emulsification of the exit streams.

$$
\begin{array}{lc}
\text { Pulse Amplitude }=2.0 \text { inches } \\
\text { Pulse Frequency }=50 \text { cycles per minute } \\
v_{D}=35 \mathrm{ft} / \mathrm{hr} & v_{C}=105 \mathrm{ft} / \mathrm{hr} \\
v_{D} / v_{C}=0.33 & v_{D}+v_{C}=140 \mathrm{ft} / \mathrm{hr}
\end{array}
$$

Over a period of time various samples were withdrawn from the column and examined visually and carefully. They gave every appearance of being free of suspended droplets. This preliminary column test was considered successful. 


\section{FIGURE 9}

\section{DETAILS OF COLUMN FILTERING APPARATUS}

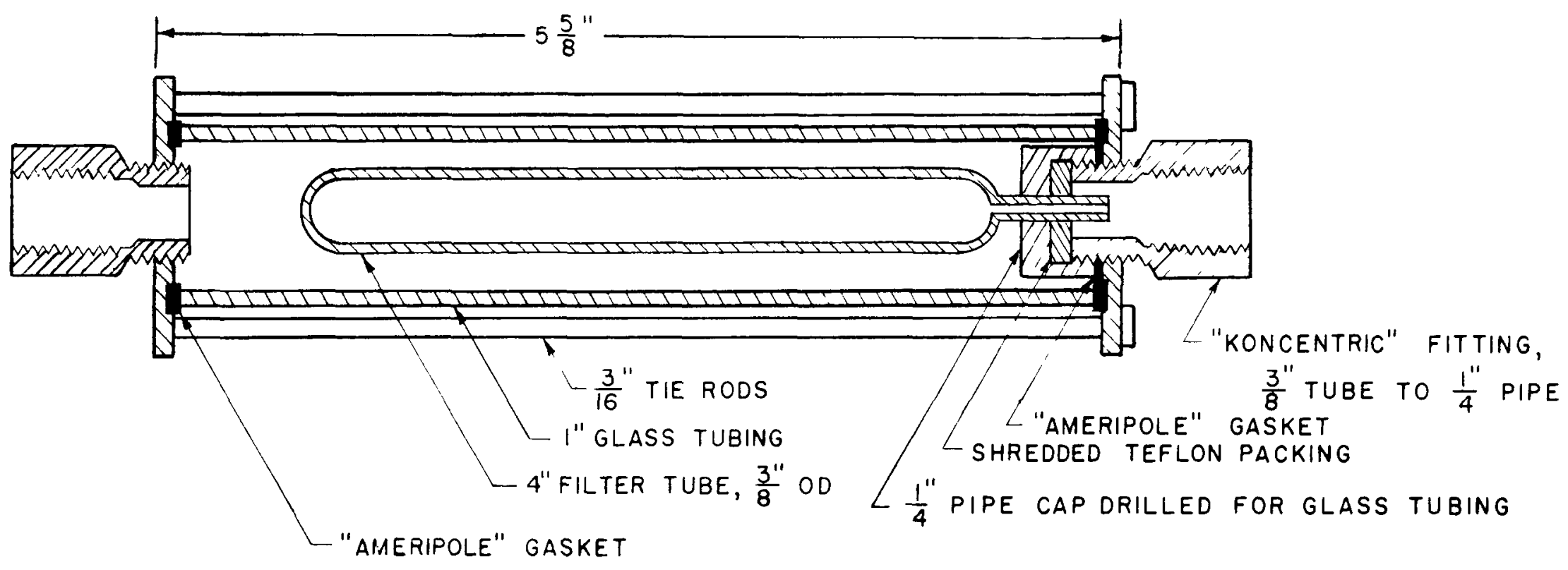




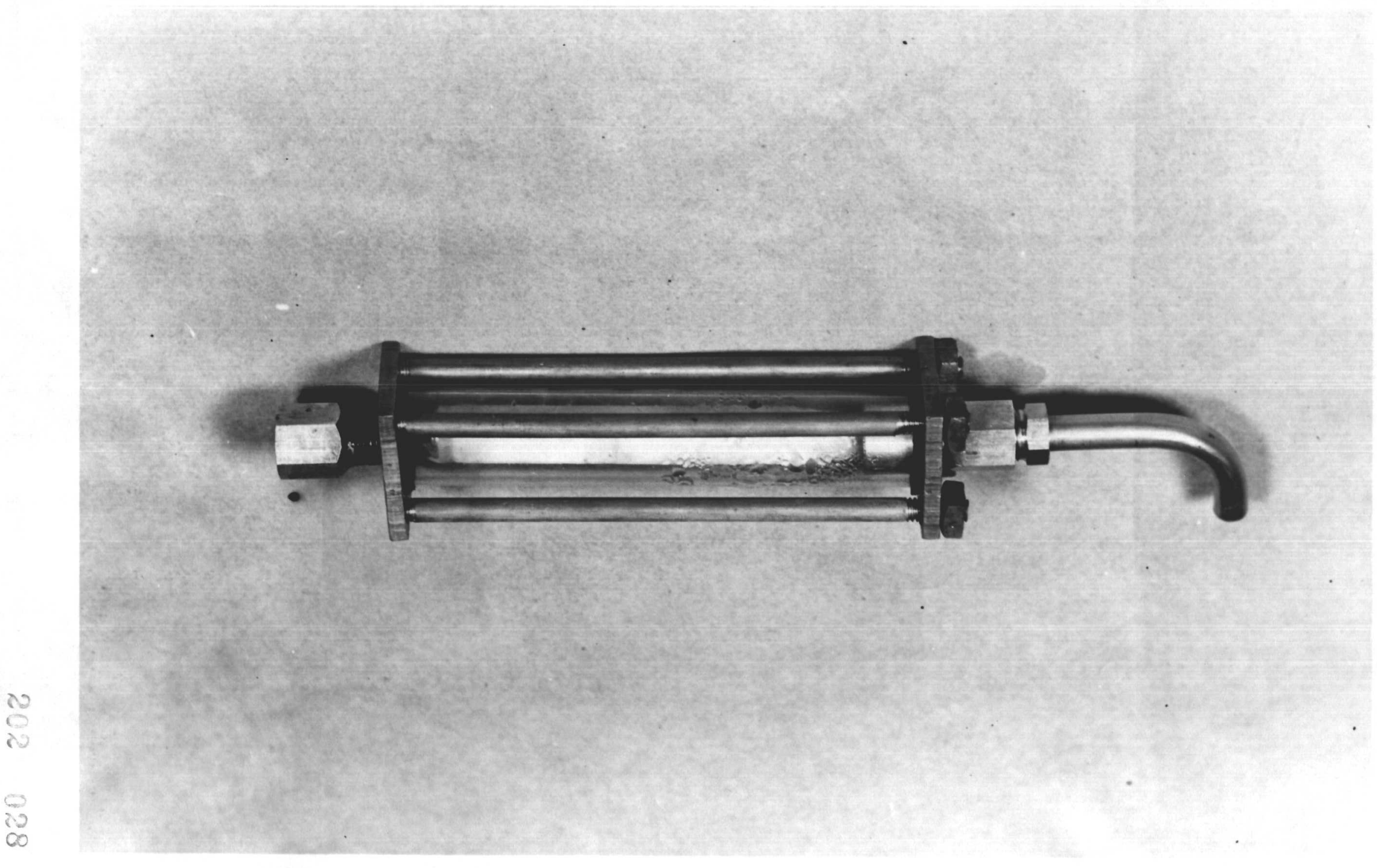

FIGURE 10 
FIGURE II

SCHEMATIC DIAGRAM OF COLUMN WITH TEMPORARY

FILTERING UNITS INSTALLED

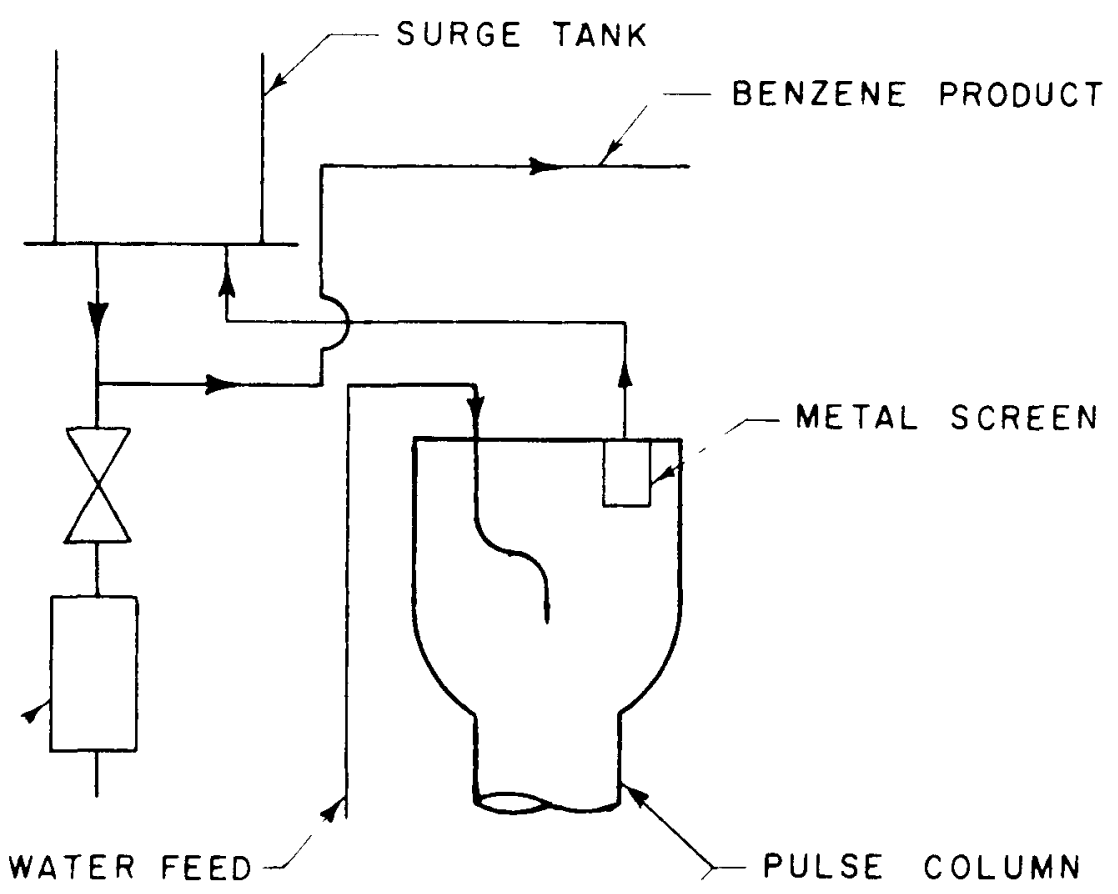

SAMPLE TAP WITH

TEMPORARY FILTERING UNIT

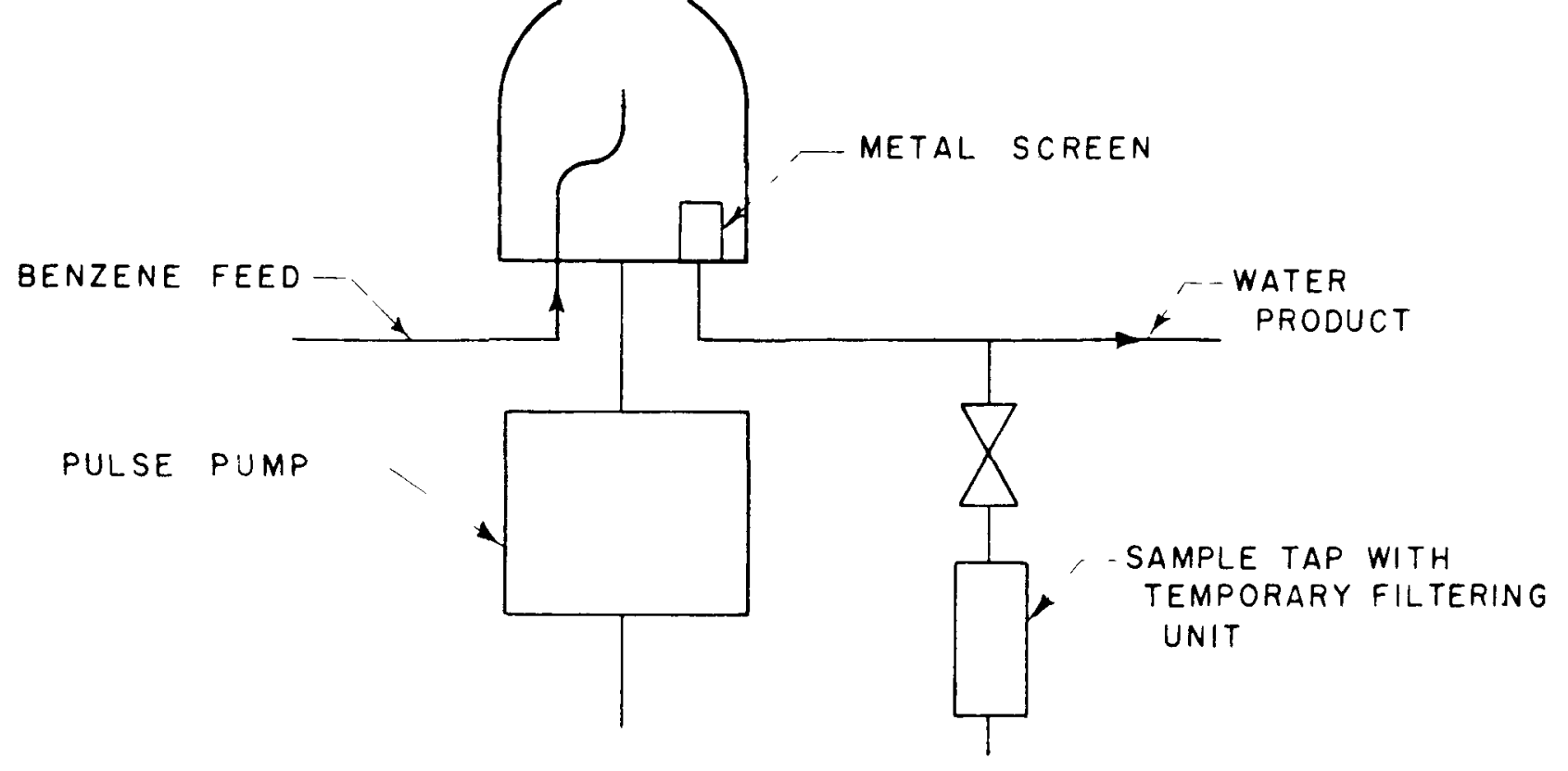


COLUMN INSTALLATION OF FILTER UNITS

Based upon the preliminary column test, permanent units were planned, constructed and installed. In part, the end connections of the pulse column were changed to permit the units to be placed in the exit lines in a manner to meet the following specifications.

1. Installation as close as practical to the point of exit from the column.

2. Installation in a vertical position, discharging upward, to avoid trapping air or vapor.

3. Location so that the hydrostatic head on the column would be adequate for the sample flow thru the filter unit.

4. Special consideration to avoid contamination.

5. Use of a medium porosity filter unit in the benzene phase, a coarse porosity unit in the water phase.

6. The sizing of the flow path of the exit streams thru the sampling zone to provide low resistance.

The sampling zones were built of standard Pyrex pipe sections and couplings, fabricated brass end plates, and "Swagelok" tubing connectors. The details of the installation at the top of the column is shown in Figure 12, that at the bottom, in Figure 13. The manner of connection of the filtertube to the sample line is shown in Figure 14.

Operation of these units has been satisfactory. The samples taken have at all times been clear with no trace of suspended particles. In addition, the analyses of the water phase for benzene have provided values less than saturation, as required. 
FILTER INSTALLATION AT TOP OF COLUMN

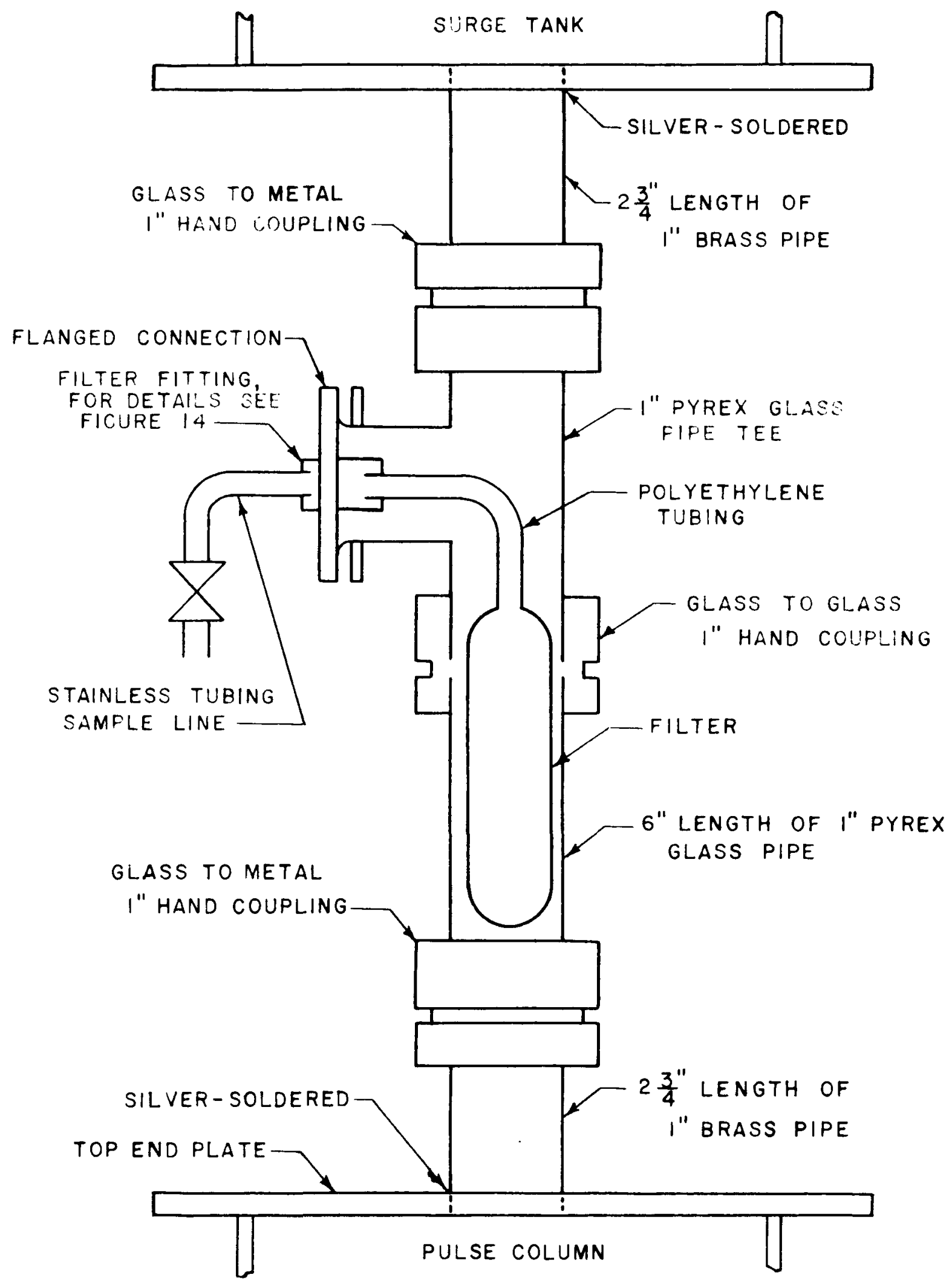




\section{FILTER INSTALLATION AT BOTTOM OF COLUMN}

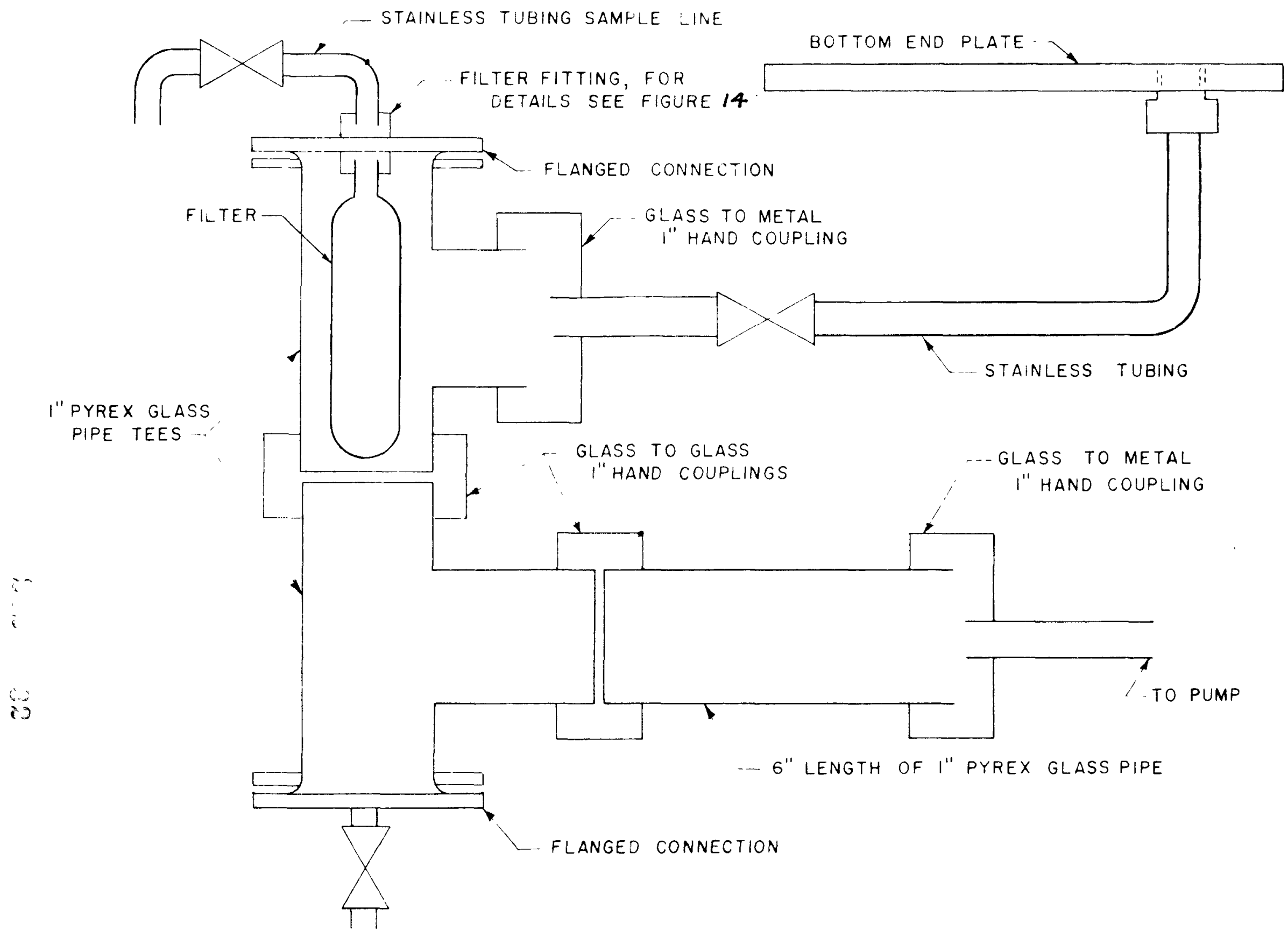


FIGURE 14

\section{DETAILS OF FILTER FITTING}

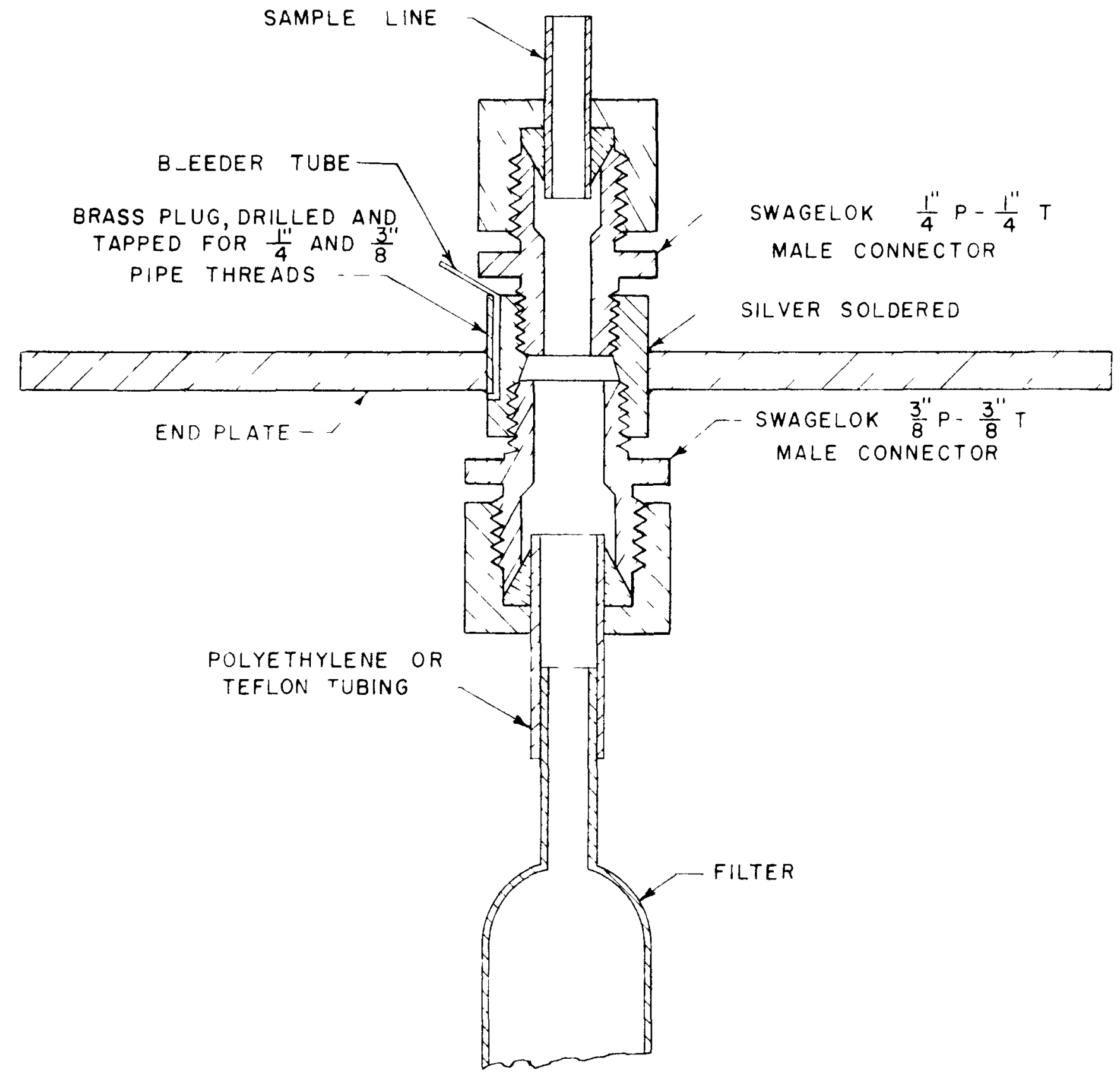




\section{INFORMATION FROM A RECENT PAPER}

A paper published recently that is pertinent to this report came to our attention after the study was completed. Jordan* has discussed the theory of separation of entrainment and emulsions by porous membranes, and has described the application of the theory to industrial problems. The separation of entrainment in each phase is carried out by means of a membrane that is preferentially wet by the phase to be filtered.

The paper presents a simple method of determining the allowable pressure-drop across a capillary bed before the dispersed phase w111 be carried through. The force necessary to cause a rupture of the interface at the capillary entrance is $\mathbf{P A}^{\prime}$, where $\mathbf{P}^{\text {is }}$ the rupture pressure and $A^{\prime}$, the capillary cross section area. The force resisting the rupture is $\sigma \mathrm{c}$, where $\sigma$ is interfacial tension (at the interface of the dispersed phase and the film wetting the caplliary wall) and c is the circumference of the capillary opening. Then

$$
\sigma \mathbf{c}=\mathbf{P A}^{\prime} \text {. }
$$

If the capillary opening is circular with a radius $r$,

$$
\begin{aligned}
& 2 \pi r \sigma=\pi r^{2} p, \text { or } \\
& \mathbf{p}=2 \sigma / r .
\end{aligned}
$$

Jordan has plotted the relationship between the maximum capillary radius of the interfacial support and the

*Jordan, G.V., Jf., Trans, ASME 77, 393-400 (1955). "Separation of immiscible liquids by means of porous membranes." 
rupture pressure for a considerable range of interfacial tensions.

From Jordan's graph, the filter-tube capillary size, and the assumption of circular capillary paths, the rupture pressure for our system can be obtained.

1. Water phase, 4" coarse porosity filter. The pore diameter from Table $I$ is 40-60 microns. Using a maximum $r=30$ microns, and assuming the thickness of the film of wetting liquid to be negligible,

$$
P=0.34 \mathrm{psi} \text { or } 0.69 \mathrm{in} \text {. Hg. }
$$

It can be seen from the pressure-drop data tabulated in the Appendix that the pressure-drop across the filter is well below this value, for a maximum sampling rate (about 0.05 psi for $200 \mathrm{ml} / \mathrm{min})$.

2. Benzene phase, 4" medium porosity filter. If the tube were preferentially wet with benzene, the value of the rupture pressure for a pore radius of 7.00 microns (Table I), obtained as above, would be about 1.2 pst or about 2.44 in. Hg. This is also well above the observed pressure drop, which was about 0.3 psi for flow rates of interest.

Since the glass is preferentially wet by water, however, perhaps the second comparison is unwarranted. This problem was recognized during the earlier investigation, but it was felt that the filter unit, in view of the small amount of dispersed phase and its apparently significant droplet size, might treat the matter as an ordinary filtration operation and exclude the unwanted water particles. The pulsing flow past the filter would tend to prevent the build-up of water 
droplets at the filter surface. In any case, the unit appears to operate in a satisfactory manner in both streams. 


\section{APPENDIX}

Page

A. Nomenclature

B. Discussion of Equations for Pressure Drop

C. Sample Calculations 36

D. Pressure-Drop and Flow Rate Data 40

E. Haze Characterization and settling Rate Studies

F. Cleaning Procedures for Tubular Frittedglass Filters 


\section{A NOMENCLATURE}

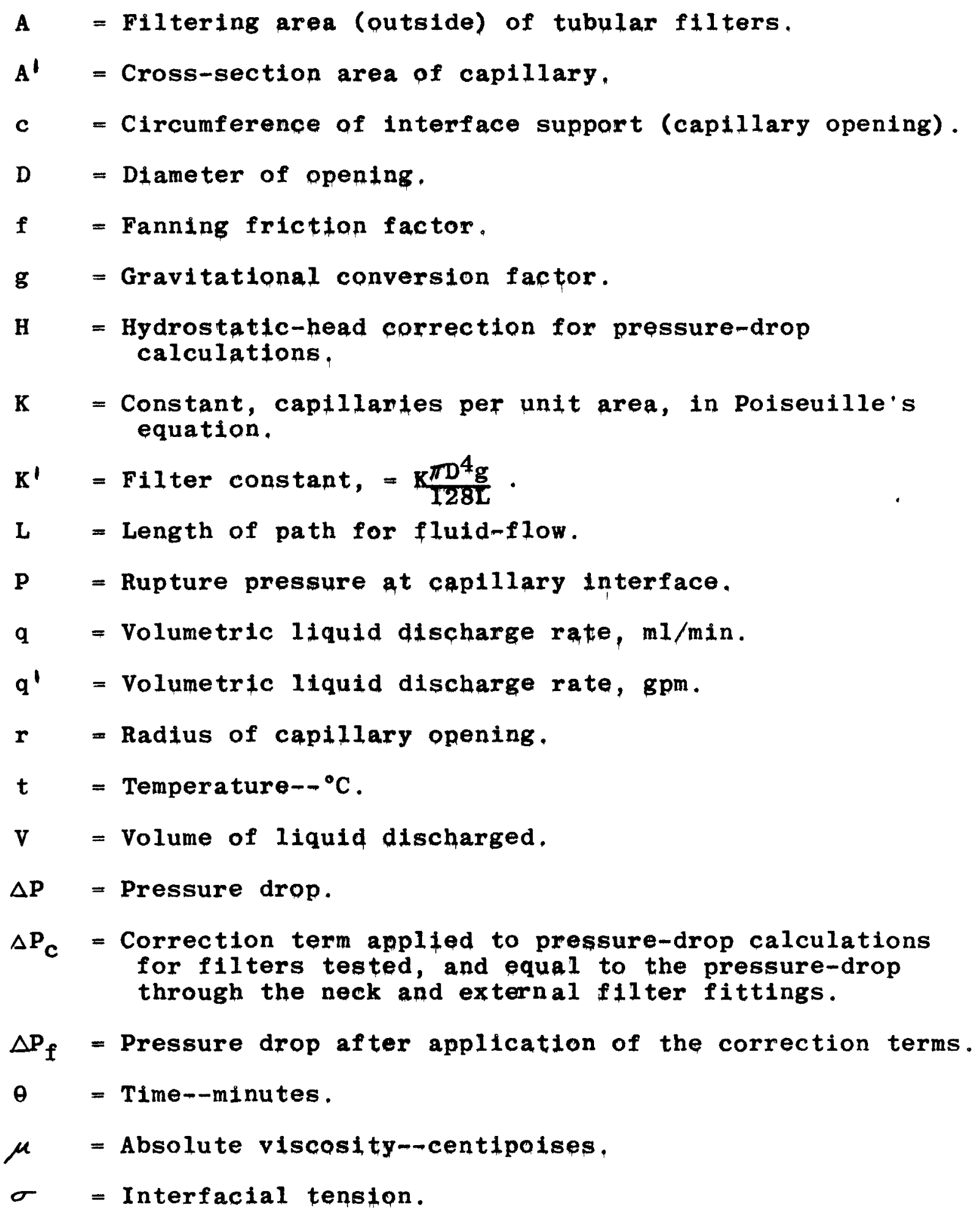




\section{B. DISCUSSION OF EQUATIONS FOR PRESSURE DROP}

According to theory, the pressure-drop behavior thru the porous path of the fllter should follow the Poisseuille equation, which is normally expressed for a filtration process as

$$
\frac{d V}{d \theta}=K \frac{\pi_{D}^{4} \Delta P g A}{128 \mu L}
$$

A constant temperature integration of the above differential equation gives

$$
\left(\frac{V}{\theta}\right)=K \frac{\pi D^{4} \Delta P g A}{128 \mu L}+\frac{C}{\theta}
$$

where $c$ is an integration constant and vanishes when $v$ and $\theta$ are taken as zero simultaneously. Substituting this boundary condition gives

$$
q=\left(\frac{K}{\theta}\right)=K \frac{\pi D^{4} \Delta P g A}{128 \mu L}
$$

Rearranging

where

$$
\frac{\mu \nu}{A \theta}=\frac{\mu}{A} g=K \frac{\pi D^{2} g}{128 L^{2}}=K^{\prime} \Delta P
$$

$$
K^{\prime}=K \frac{\pi D^{4 g}}{128 L}
$$

is a characteristic constant for a given filter and is represented by $K^{\prime}$.

Thus the characteristic constant is equal to the slope of the line obtained by plotting $\frac{\mu V}{A \theta}$ as a function of pressure drop. These constants may be computed and tabulated for the various filters, This straight-1ine relationship, of course, assumes no plugging of the filter pores due to what might be considered a "filter-cake."

The pressure drop thru the neck of the tubular filter should follow the Fanning equation, which may be written

$$
\Delta P=\frac{32 f L^{\prime} q^{2}}{\pi^{2} g D^{5}}
$$


feet of fluid flowing.

Assuming that the empirical friction factor $f$ is constant, this equation predicts that the volumetric flow rate of a specified fluid through a given clrcular channel is proportional to the square root of the pressure drop. Furthermore, a logarithmic plot of volumetric flow rate as a function of pressure drop through a given circular channel should, again assuming constancy of the friction factor, give a straight line having a slope of $1 / 2$.

A close examination of Figure 5 , which is a logarithmic plot of the flow rate vs the pressure drop measured for a glass tube of approximately the same dimension as the neck of a filter tube, reveals a slight curvature in the line obtained. Also, the slope is a little less than the expected value of $1 / 2$. This apparent discrepancy with the theory can be attributed to the erronefous assumption of constancy in the friction factor. Actually, this factor is not constant, but for a given pipe is a function of the Reynolds number

By correcting the total pressure-drop measured for the pressure-drop thru the neck of the tube (obtained from Figure $5)$, the pressure-drop line for the filter section can be obtained. The filter constants discussed above are measured from this "corrected" curve.

A sample calculation and the tabulated data and calculation results are given in the following sections. 


\section{SAMPLE CALCULATIONS}

A sample calculation is shown for the last data point in Table IV, corresponding to water flowing through a fourinch, coarse porosity filter under an apparent pressure-drop of three inches of mercury. The raw data indicate that $1000 \mathrm{ml}$ of distilled water is $28.8^{\circ} \mathrm{C}$ under a pressure differential of three Inches of $\mathrm{Hg}$ will flow through the filter and neck in 0.285 minutes. This corresponds to a volumetric flow rate of

$$
\begin{aligned}
\frac{V}{\theta}=q & =\frac{1000 \mathrm{ml}}{0.285 \mathrm{~min}}=3508 \frac{\mathrm{ml}}{\mathrm{min}}, \text { or } q^{\prime}=3508 \frac{\mathrm{ml}}{\mathrm{min}} \times .0002642 \frac{\mathrm{gal}}{\mathrm{ml}} \\
& =0.927 \mathrm{gpm} .
\end{aligned}
$$

Reference to Figure 15 indicates that the viscosity of water at $28.8^{\circ} \mathrm{C}$ is 0.822 centipoises. Thus

$$
\mu q^{\prime}=(0.822 \mathrm{cps})(0.927 \mathrm{gpm})=0.762 \frac{\mathrm{cps}-\mathrm{gal}}{\mathrm{min}}
$$

Since the filtering area for this particular filter is 7.556 in. ${ }^{2}$,

$$
\frac{\mu_{A}}{q^{\prime}}=\left(0.762 \frac{\mathrm{cp}-\mathrm{gal}}{\mathrm{min}}\right)\left(\frac{1}{7.556 \text { in. }}\right)=0.1008 \frac{\mathrm{cp}-\mathrm{gal}}{\mathrm{in.}^{2}-\mathrm{min} .}
$$

The hydrostatic head on the filter was approximately 2.0 inches of water. Th 1 s corresponds to about 0.15 inches of mercury. The total pressure drop across the filter and external fittings, then, is $3 \mathrm{in.} \mathrm{Hg} \mathrm{plus} 0.15 \mathrm{in}$, $\mathrm{Hg}$, or $3.15 \mathrm{in.} \mathrm{Hg}$. Reference to Figure 5 indlcates that the pressure drop through the external fittings at a flow rate of $0.927 \mathrm{gpm}$ is about $1.10 \mathrm{in.} \mathrm{Hg}$. Therefore, the pressure drop across the porous medium itself is $3.15 \mathrm{in}$. $\mathrm{Hg}$ minus $1.10 \mathrm{in}$. $\mathrm{Hg}$, or $2.05 \mathrm{in.} \mathrm{Hg}$. 
The calculations for benzene were made in a similar manner, using the appropriate information. The viscosity of benzene was obtained from Figure 16. 


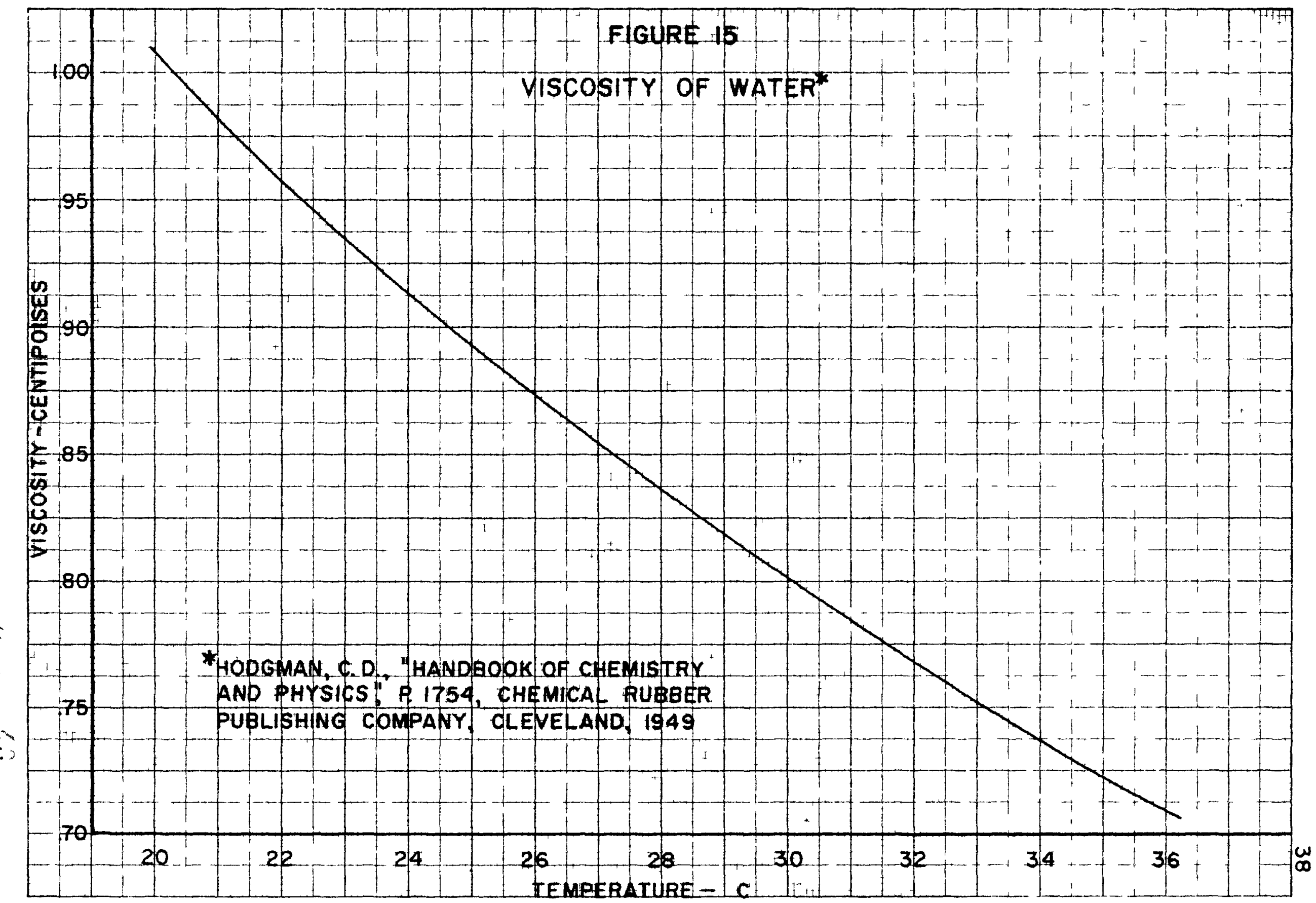




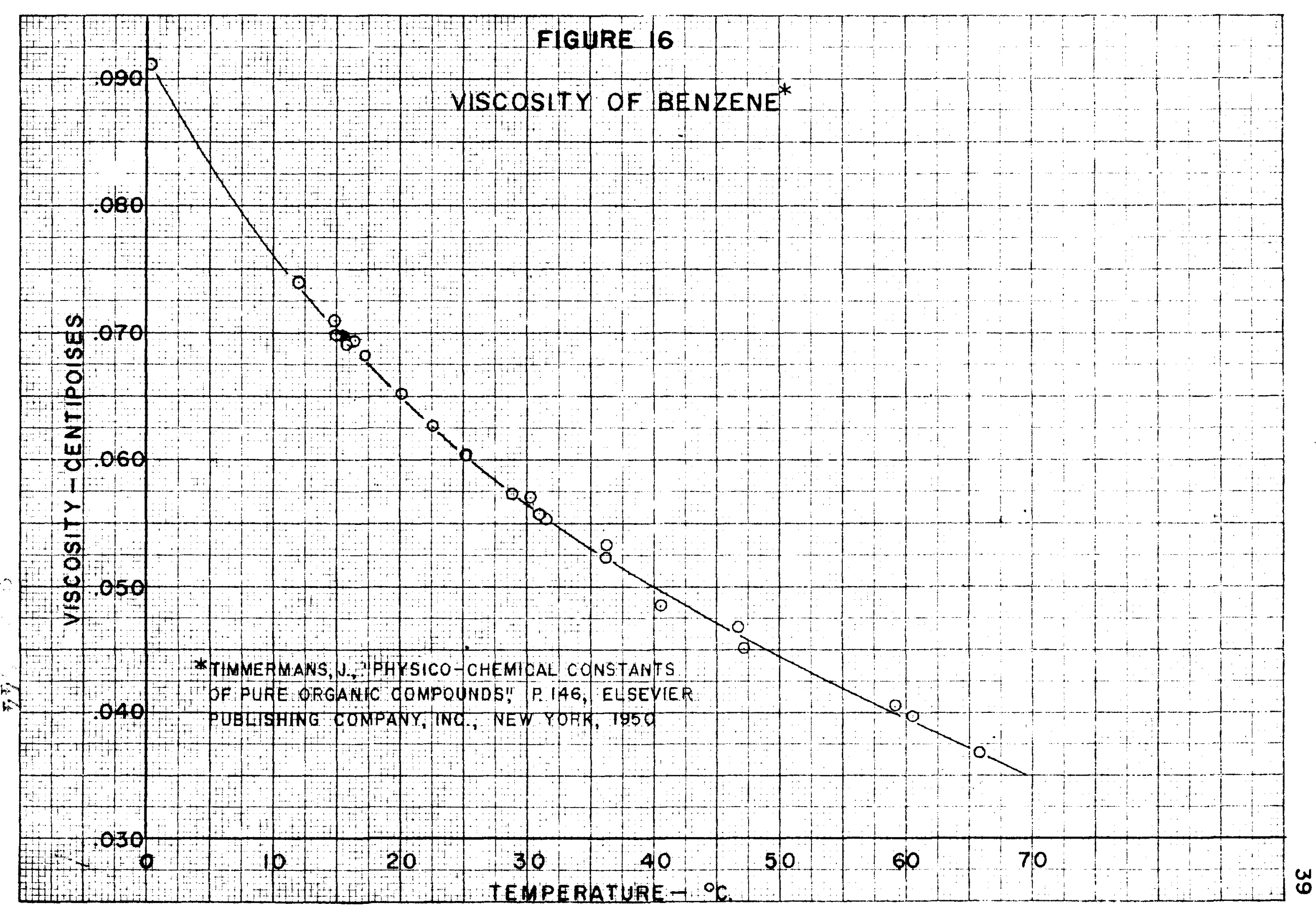


D. PRESSURE-DROP AND FLON-RATE DATA

TABLE III

Pressure-Drop and Plow-Rate Data for Water Flowing thru Simulated FiTter-iube Neck and External Fittings

\begin{tabular}{|c|c|c|c|c|c|c|}
\hline$\stackrel{\Delta p}{\text { in. } H_{2} \mathrm{O}}$ & $\underset{m 1 .}{v}$ & $\begin{array}{c}\theta \\
m i n\end{array}$ & ${ }^{\circ} \mathrm{C}$ & $\stackrel{\Delta \mathrm{p}}{\mathrm{in} . \mathrm{Hg}}$ & $\begin{array}{l}\mathrm{q}=\mathrm{V} / \theta \\
\mathrm{m} 1 / \mathrm{min}\end{array}$ & $\begin{array}{r}q^{\prime} \\
\text { gpm }\end{array}$ \\
\hline 1 & 1000 & 0.78 & 30.7 & 0.0735 & 1282 & 0.339 \\
\hline 1 & 1000 & .76 & 30,7 &, 0735 & 1316 & .348 \\
\hline 2 & 1000 & .64 & 30.7 & .147 & 1562 & .413 \\
\hline 2 & 1000 & .63 & 30.7 & .147 & 1587 & .419 \\
\hline 3 & 1000 & .55 & 30.5 & .221 & 1818 & .480 \\
\hline 3 & 1000 & .56 & 30.5 & .221 & 1785 & .472 \\
\hline 4 & 1000 & .49 & 30.6 &, 294 & 2040 & .539 \\
\hline 4 & 1000 & .50 & 30.7 & .294 & 2000 & .528 \\
\hline 5 & 1000 &, 46 & 30.7 & .368 & 2174 & .574 \\
\hline 5 & 1000 & .46 & 30.6 & .368 & 2174 & .574 \\
\hline 6 & 1000 & .42 & 30.6 & .441 & 2381 & .629 \\
\hline 6 & 1000 & .42 & 30.7 & .447 & 2381 & .629 \\
\hline 8 & 1000 & .38 & 30.7 & .588 & 2632 & .695 \\
\hline 10 & 1000 & .34 & 30.7 & .735 & 2941 & .777 \\
\hline 12 & 1000 & .31 & 30.7 & .882 & 3226 & .852 \\
\hline
\end{tabular}


TABLE IV

Data for the Filtration of Distilled Water with a 4-inch Coarse-porosity Filter

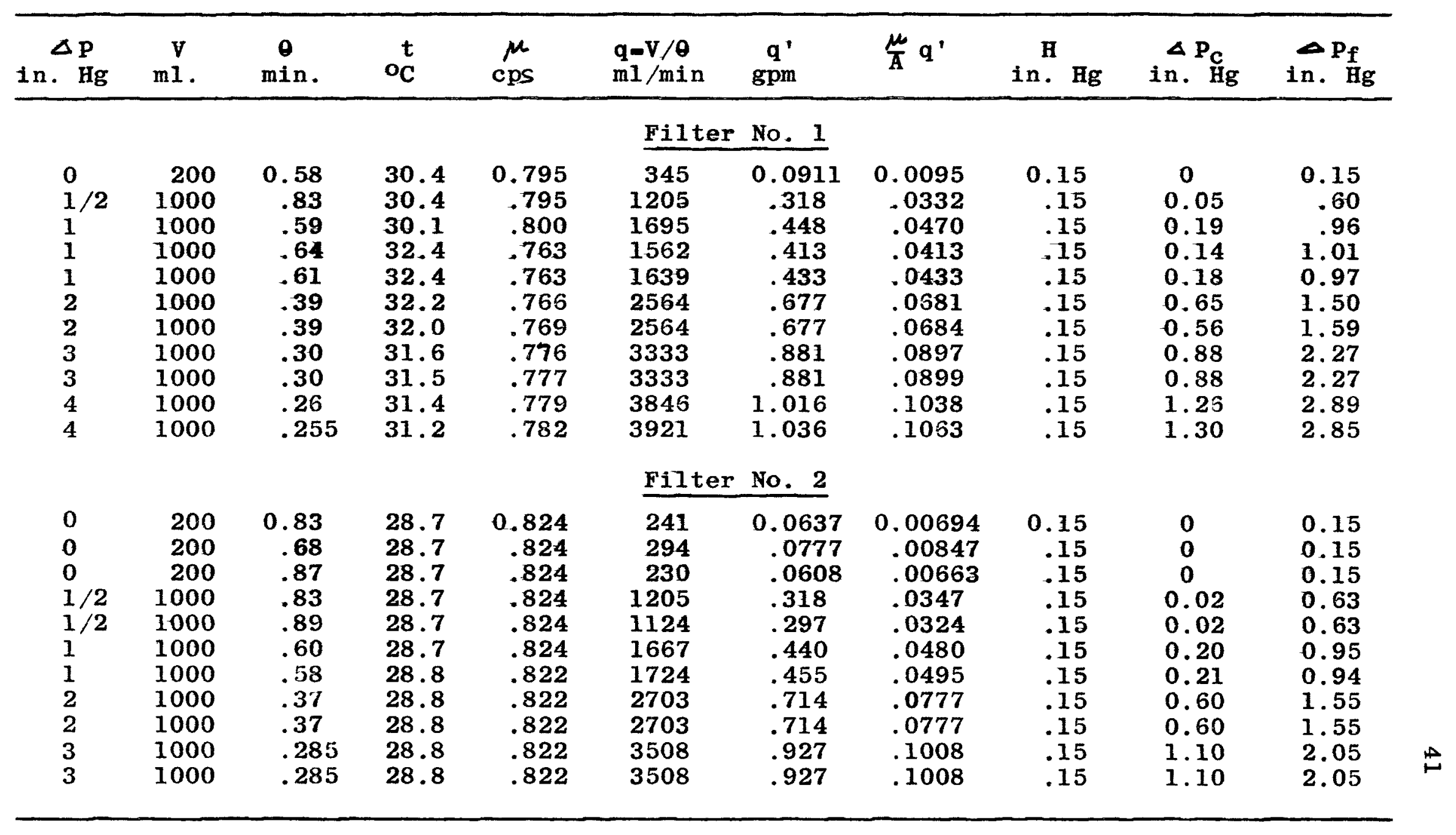


TABLE V

Data for the Filtration of Distilled Water with a 4-inch Medium-porosity Filter

\begin{tabular}{|c|c|c|c|c|c|c|c|c|c|c|}
\hline$\stackrel{\Delta p}{i n . ~ H g}$ & $\begin{array}{c}\mathrm{V} \\
\mathrm{m} \mathbf{1}\end{array}$ & $\stackrel{\theta}{\min }$. & ${ }^{t} \mathrm{C}$ & $\mu_{c p}$ & $\begin{array}{l}q=v / \theta \\
\mathrm{m} 1 / \mathrm{min}\end{array}$ & $\underset{\mathrm{gpm}}{\mathrm{q}^{\prime}}$ & $\frac{\mu}{A} q^{\prime}$ & in. ${ }^{\mathrm{H}} \mathrm{Hg}$ & $\underset{\text { in. }}{\Delta \mathrm{P}_{\mathrm{C}}}$ & $\underset{\text { in. }}{\Delta P_{f}}$ \\
\hline & \multicolumn{10}{|c|}{ Filter No. 1} \\
\hline $\begin{array}{l}1 \\
1 \\
2 \\
2 \\
3 \\
3 \\
4 \\
4 \\
5 \\
5 \\
6 \\
6\end{array}$ & $\begin{array}{l}200 \\
200 \\
200 \\
200 \\
200 \\
200 \\
200 \\
200 \\
200 \\
200 \\
200 \\
200\end{array}$ & $\begin{array}{l}0.975 \\
.980 \\
.54 \\
.555 \\
.395 \\
.395 \\
.31 \\
.31 \\
.245 \\
.250 \\
.210 \\
.220\end{array}$ & $\begin{array}{l}28.8 \\
28.8 \\
28.8 \\
28.8 \\
28.8 \\
28.8 \\
28.8 \\
28.8 \\
28.8 \\
28.8 \\
28.8 \\
28.8\end{array}$ & $\begin{array}{r}0.822 \\
.822 \\
.822 \\
.822 \\
.822 \\
.822 \\
.822 \\
.822 \\
.822 \\
.822 \\
.822 \\
.822\end{array}$ & $\begin{array}{l}205 \\
204 \\
370 \\
360 \\
506 \\
506 \\
645 \\
645 \\
816 \\
800 \\
952 \\
909\end{array}$ & $\begin{array}{r}0.0542 \\
.0539 \\
.0978 \\
.0951 \\
.134 \\
.134 \\
.170 \\
.170 \\
.216 \\
.211 \\
.252 \\
.240\end{array}$ & $\begin{array}{c}0.00607 \\
.00603 \\
.0109 \\
.0106 \\
.0150 \\
.0150 \\
.0191 \\
.0191 \\
.0242 \\
.0236 \\
.0282 \\
.0268\end{array}$ & $\begin{array}{r}0.15 \\
.15 \\
.15 \\
.15 \\
.15 \\
.15 \\
.15 \\
.15 \\
.15 \\
.15 \\
.15 \\
.15\end{array}$ & $\begin{array}{l}0 \\
0 \\
0 \\
0 \\
0 \\
0 \\
0 \\
0 \\
0 \\
0 \\
0 \\
0\end{array}$ & $\begin{array}{l}1.15 \\
1.15 \\
2.15 \\
2.15 \\
3.15 \\
3.15 \\
4.15 \\
4.15 \\
5.15 \\
5.15 \\
6.15 \\
6.15\end{array}$ \\
\hline 6 & \multicolumn{10}{|c|}{ Filter No. 2} \\
\hline $\begin{array}{l}1 \\
1 \\
2 \\
2 \\
3 \\
3 \\
4 \\
4 \\
5 \\
5 \\
6 \\
6\end{array}$ & $\begin{array}{l}200 \\
200 \\
200 \\
200 \\
200 \\
200 \\
200 \\
200 \\
200 \\
200 \\
200 \\
200\end{array}$ & $\begin{array}{c}3.29 \\
3.01 \\
1.72 \\
1.73 \\
1.22 \\
1.25 \\
.98 \\
.98 \\
.82 \\
.81 \\
.68 \\
.685\end{array}$ & $\begin{array}{l}29.0 \\
29.0 \\
29.0 \\
29.0 \\
30.4 \\
30.4 \\
30.0 \\
30.0 \\
29.8 \\
29.8 \\
29.8 \\
29.8\end{array}$ & $\begin{array}{r}0.818 \\
.818 \\
.818 \\
.818 \\
.795 \\
.795 \\
.802 \\
.802 \\
.822 \\
.822 \\
.822 \\
.822\end{array}$ & $\begin{array}{l}60.8 \\
66.4 \\
116 \\
116 \\
164 \\
160 \\
204 \\
204 \\
244 \\
247 \\
294 \\
292\end{array}$ & $\begin{array}{r}0.0161 \\
.0175 \\
.0306 \\
.0306 \\
.0433 \\
.0420 \\
.0539 \\
.0539 \\
.0644 \\
.0653 \\
.0377 \\
.0771\end{array}$ & $\begin{array}{c}0.00176 \\
.00191 \\
.0033 \\
.0033 \\
.00459 \\
.00446 \\
.00577 \\
.00577 \\
.00707 \\
.00717 \\
.00854 \\
.00847\end{array}$ & $\begin{array}{l}0.15 \\
.15 \\
.15 \\
.15 \\
.15 \\
.15 \\
.15 \\
.15 \\
.15 \\
.15 \\
.15 \\
.15\end{array}$ & $\begin{array}{l}0 \\
0 \\
0 \\
0 \\
0 \\
0 \\
0 \\
0 \\
0 \\
0 \\
0 \\
0\end{array}$ & $\begin{array}{l}1.15 \\
1.15 \\
2.15 \\
2.15 \\
3.15 \\
3.15 \\
4.15 \\
4.15 \\
5.15 \\
5.15 \\
6.15 \\
6.15\end{array}$ \\
\hline
\end{tabular}


TABLE VI

Data for the Filtration of Distilled Water with a 2-inch Coarse-porosity Filter

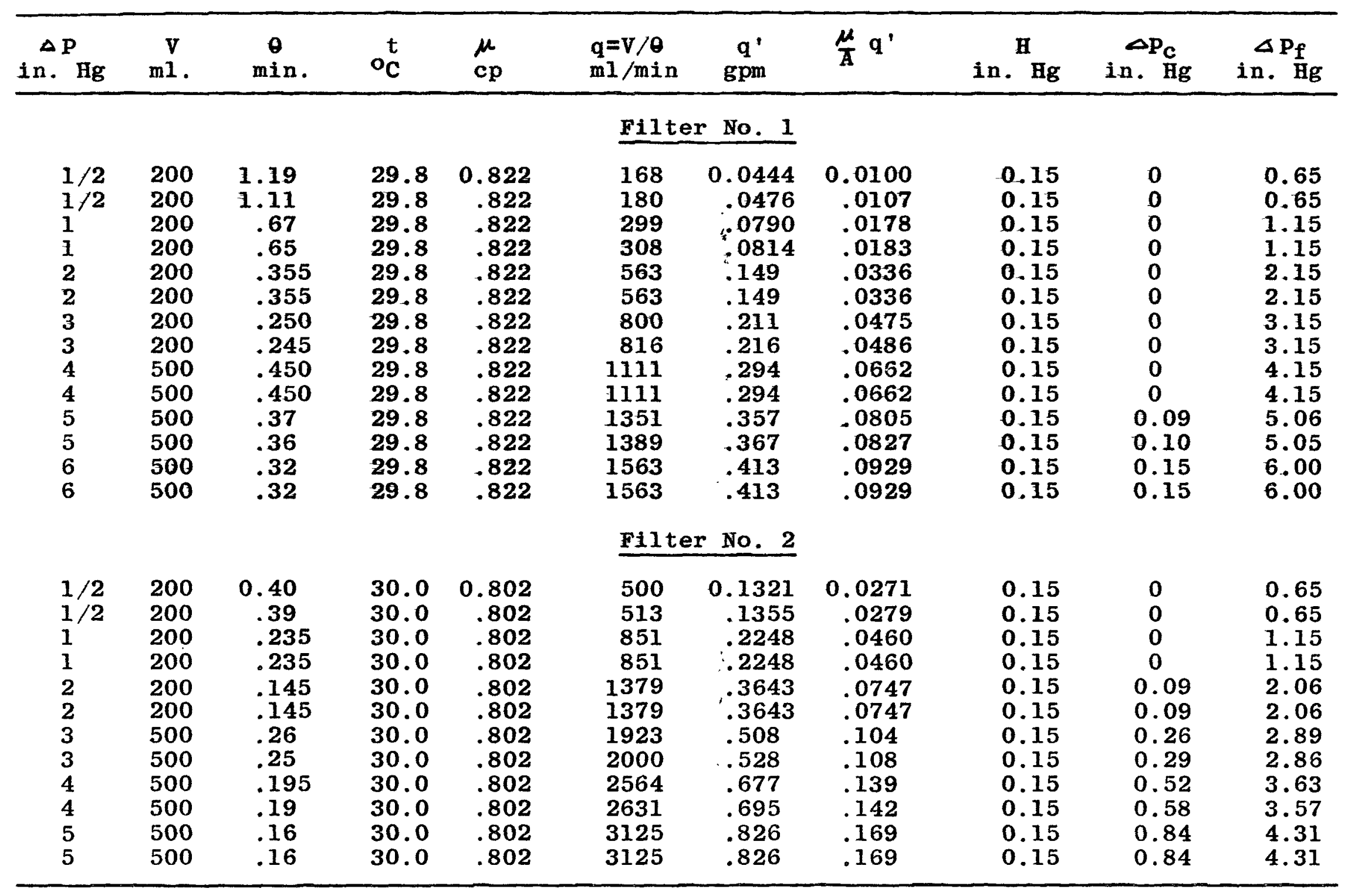


TABLE VII

Data for the Filtration of Benzene with a 4-inch Coarse-porosity Filter

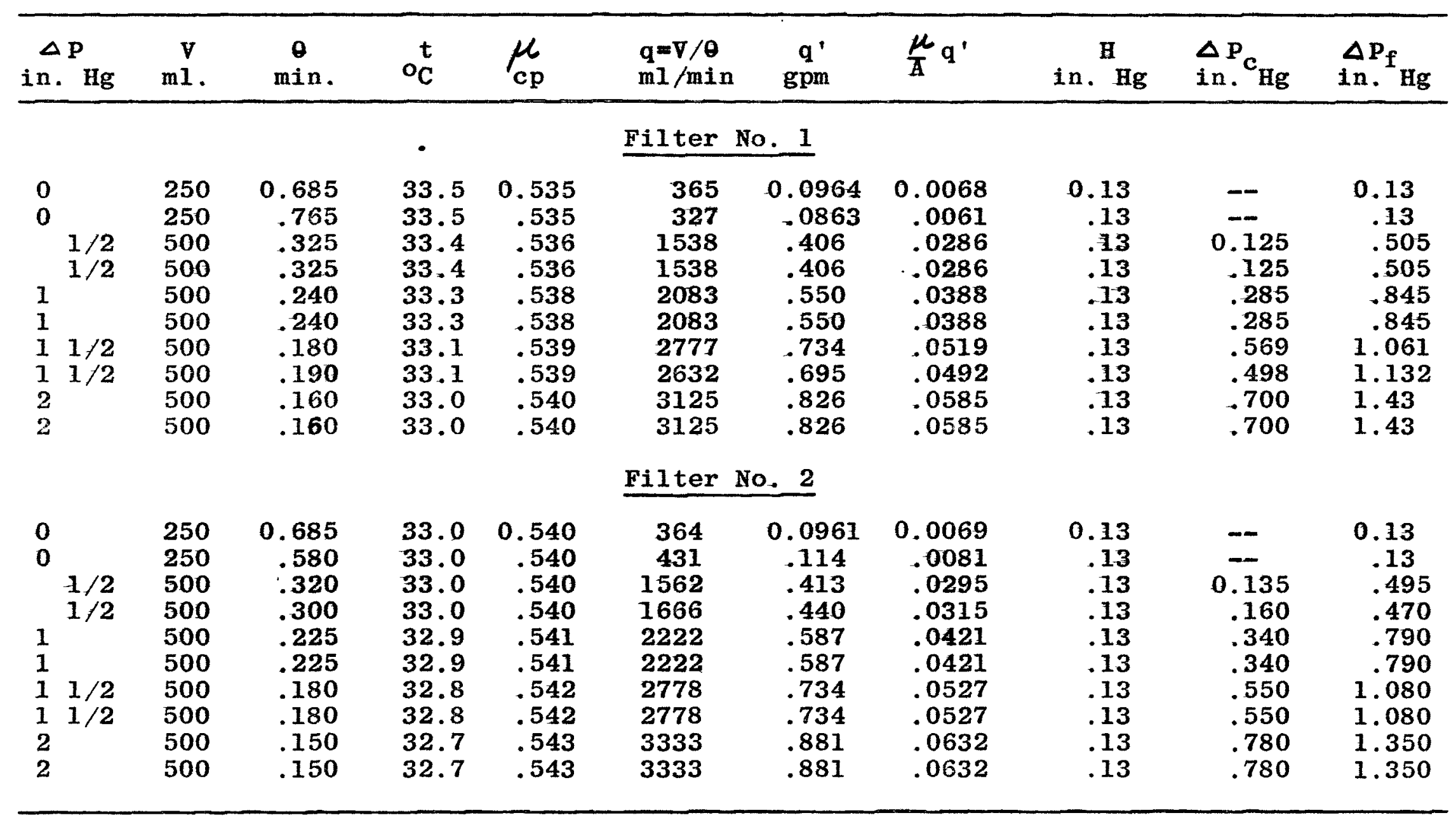


TABLE VIII

Data for the Filtration of Benzene with a 4-inch Medium-porosity Filter

\begin{tabular}{|c|c|c|c|c|c|c|c|c|c|c|}
\hline$\stackrel{\Delta \mathbf{p}}{\mathrm{in} .} \mathrm{Hg}$ & $\begin{array}{c}\mathrm{V} \\
\mathrm{ml}\end{array}$ & $\begin{array}{c}\theta \\
\text { min. }\end{array}$ & ${ }^{t} \mathrm{C}$ & $\begin{array}{l}\mu \\
c p\end{array}$ & $\begin{array}{l}q=V / \theta \\
m 1 / m i n\end{array}$ & $\underset{\mathrm{gpm}}{\mathbf{q}^{\prime}}$ & $\frac{\mu}{A} q^{\prime}$ & in. $\stackrel{H}{H} \mathbf{g}$ & $\begin{array}{l}\Delta P_{c} \\
\text { in. }{ }^{H g}\end{array}$ & $\begin{array}{l}\Delta P_{f} \\
\text { in. }{ }^{\prime} H g\end{array}$ \\
\hline \multicolumn{11}{|c|}{ Filter No. 1} \\
\hline $\begin{array}{ll} & 1 / 2 \\
& 1 / 2 \\
1 & \\
1 & \\
1 & 1 / 2 \\
1 & 1 / 2 \\
2 & \\
2 & \\
2 & 1 / 2 \\
2 & 1 / 2 \\
3 & \\
3 & \\
4 & \\
4 & \\
5 & \\
5 & \end{array}$ & $\begin{array}{l}250 \\
250 \\
250 \\
250 \\
250 \\
250 \\
250 \\
250 \\
250 \\
250 \\
250 \\
250 \\
250 \\
250 \\
250 \\
250\end{array}$ & $\begin{array}{l}1.24 \\
1.22 \\
.770 \\
.770 \\
.560 \\
.550 \\
.445 \\
.435 \\
.365 \\
.370 \\
.325 \\
.325 \\
.250 \\
.250 \\
.205 \\
.205\end{array}$ & $\begin{array}{l}33.3 \\
33.3 \\
33.1 \\
33.1 \\
32.9 \\
32.9 \\
32.9 \\
32.9 \\
32.9 \\
32.9 \\
32.9 \\
32.9 \\
32.9 \\
32.9 \\
32.9 \\
32.9\end{array}$ & $\begin{array}{r}0.538 \\
.538 \\
.539 \\
.539 \\
.541 \\
.541 \\
.541 \\
.541 \\
.541 \\
.541 \\
.541 \\
.541 \\
.541 \\
.541 \\
.541 \\
.541\end{array}$ & $\begin{array}{r}201 \\
205 \\
325 \\
325 \\
446 \\
455 \\
562 \\
575 \\
685 \\
676 \\
769 \\
769 \\
1000 \\
1000 \\
1219 \\
1219\end{array}$ & $\begin{array}{c}0.0531 \\
.0542 \\
.0859 \\
.0859 \\
.118 \\
.120 \\
.148 \\
.152 \\
.181 \\
.179 \\
.203 \\
.203 \\
.264 \\
.264 \\
.322 \\
.322\end{array}$ & $\begin{array}{r}0.0039 \\
.0040 \\
.0063 \\
.0063 \\
.0087 \\
.0088 \\
.0109 \\
.0112 \\
.0113 \\
.0132 \\
.0150 \\
.0150 \\
.0195 \\
.0195 \\
.0237 \\
.0237\end{array}$ & $\begin{array}{r}0.13 \\
.13 \\
.13 \\
.13 \\
.13 \\
.13 \\
.13 \\
.13 \\
.13 \\
.13 \\
.13 \\
.13 \\
.13 \\
.13 \\
.13 \\
.13\end{array}$ & $\begin{array}{l}-- \\
-- \\
=- \\
-- \\
-- \\
-- \\
-- \\
-- \\
-- \\
-- \\
-- \\
-- \\
--\end{array}$ & $\begin{array}{l}0.63 \\
0.63 \\
1.13 \\
1.13 \\
1.63 \\
1.63 \\
2.13 \\
2.13 \\
2.63 \\
2.63 \\
3.13 \\
3.13 \\
4.13 \\
4.13 \\
5.13 \\
5.13\end{array}$ \\
\hline \multicolumn{11}{|c|}{ Filter No. 2} \\
\hline $\begin{array}{l}1 \\
1 \\
2 \\
2 \\
3 \\
3 \\
4 \\
4 \\
5 \\
5\end{array}$ & $\begin{array}{l}250 \\
250 \\
250 \\
250 \\
250 \\
250 \\
250 \\
250 \\
250 \\
250\end{array}$ & $\begin{array}{c}2.69 \\
2.42 \\
1.35 \\
1.36 \\
.96 \\
.96 \\
.755 \\
.755 \\
.605 \\
.605\end{array}$ & $\begin{array}{l}33.4 \\
33.4 \\
33.3 \\
33.3 \\
33.3 \\
33.3 \\
33.1 \\
33.1 \\
33.1 \\
33.1\end{array}$ & $\begin{array}{r}0.536 \\
.536 \\
.538 \\
.538 \\
.538 \\
.538 \\
.539 \\
.539 \\
.539 \\
.539\end{array}$ & $\begin{array}{r}92.9 \\
103.3 \\
185 \\
184 \\
260 \\
260 \\
331 \\
331 \\
413 \\
413\end{array}$ & $\begin{array}{r}0.0246 \\
.0272 \\
.0489 \\
.0486 \\
.0687 \\
.0687 \\
.0875 \\
.0875 \\
.1090 \\
.1090\end{array}$ & $\begin{array}{r}0.0018 \\
.0020 \\
.0035 \\
.0035 \\
.0050 \\
.0050 \\
.0063 \\
.0063 \\
.0079 \\
.0079\end{array}$ & $\begin{array}{r}0.13 \\
.13 \\
.13 \\
.13 \\
.13 \\
.13 \\
.13 \\
.13 \\
.13 \\
.13\end{array}$ & $\begin{array}{l}-- \\
-- \\
-- \\
-- \\
-- \\
-- \\
-- \\
--\end{array}$ & $\begin{array}{l}1.13 \\
1.13 \\
2.13 \\
2.13 \\
3.13 \\
3.13 \\
4.13 \\
4.13 \\
5.13 \\
5.13\end{array}$ \\
\hline
\end{tabular}


TABLE IX

Data for the Filtration of Benzene with a 2-inch Coarse-porosity Filter

\begin{tabular}{|c|c|c|c|c|c|c|c|c|c|c|}
\hline$\underset{\text { in. }}{\Delta \mathrm{Pg}}$ & $\begin{array}{c}\mathrm{v} \\
\mathrm{m} 1 .\end{array}$ & $\stackrel{\theta}{\min .}$ & ${ }^{t}$ & $\begin{array}{l}\mu . \\
c p\end{array}$ & $\begin{array}{l}q=v / \theta \\
\mathrm{m} 1 / \mathrm{min}\end{array}$ & $\begin{array}{l}q^{\prime} \\
\mathrm{gpm}\end{array}$ & $\frac{\mu}{\bar{A}} q^{\prime}$ & $\stackrel{\text { in }}{\mathrm{H}} \mathrm{Hg}$ & $\begin{array}{l}\Delta P_{c_{H g}} \\
\text { in. }\end{array}$ & $\underset{\mathbf{i n} .}{\Delta \mathbf{P}_{\mathbf{f}}}$ \\
\hline
\end{tabular}

Filter No. 1

\begin{tabular}{|c|c|c|c|c|c|c|c|c|c|c|}
\hline $\begin{array}{l}1 / 2 \\
1 / 2\end{array}$ & $\begin{array}{l}250 \\
250 \\
250 \\
250 \\
250 \\
250 \\
250 \\
250 \\
500 \\
500 \\
500 \\
500\end{array}$ & $\begin{array}{r}0.685 \\
.685 \\
.435 \\
.450 \\
.270 \\
.280 \\
.200 \\
.200 \\
.32 \\
.33 \\
.27 \\
.27\end{array}$ & $\begin{array}{l}33.0 \\
33.0 \\
33.0 \\
33.0 \\
33.0 \\
33.0 \\
32.9 \\
32.9 \\
32.8 \\
32.8 \\
32.7 \\
32.7\end{array}$ & $\begin{array}{r}0.540 \\
.540 \\
.540 \\
.540 \\
.540 \\
.540 \\
.541 \\
.541 \\
.542 \\
.542 \\
.543 \\
.543\end{array}$ & $\begin{array}{r}365 \\
365 \\
575 \\
556 \\
926 \\
892 \\
1250 \\
1250 \\
1563 \\
1515 \\
1852 \\
1852\end{array}$ & $\begin{array}{c}0.0964 \\
.0964 \\
.152 \\
.147 \\
.245 \\
.236 \\
.330 \\
.330 \\
.413 \\
.400 \\
.489 \\
.489\end{array}$ & $\begin{array}{r}0.0143 \\
.0143 \\
.0225 \\
.0217 \\
.0362 \\
.0349 \\
.0490 \\
.0490 \\
.0611 \\
.0592 \\
.0723 \\
.0723\end{array}$ & $\begin{array}{r}0.13 \\
.13 \\
.13 \\
.13 \\
.13 \\
.13 \\
.13 \\
.13 \\
.13 \\
.13 \\
.13 \\
.13\end{array}$ & $\begin{array}{l}-- \\
-- \\
-- \\
-- \\
-- \\
-- \\
-- \\
-- \\
0.133 \\
.116 \\
.210 \\
.210\end{array}$ & $\begin{array}{l}0.63 \\
0.63 \\
1.13 \\
1.13 \\
2.13 \\
2.13 \\
3.13 \\
3.13 \\
3.997 \\
4.014 \\
4.92 \\
4.92\end{array}$ \\
\hline
\end{tabular}

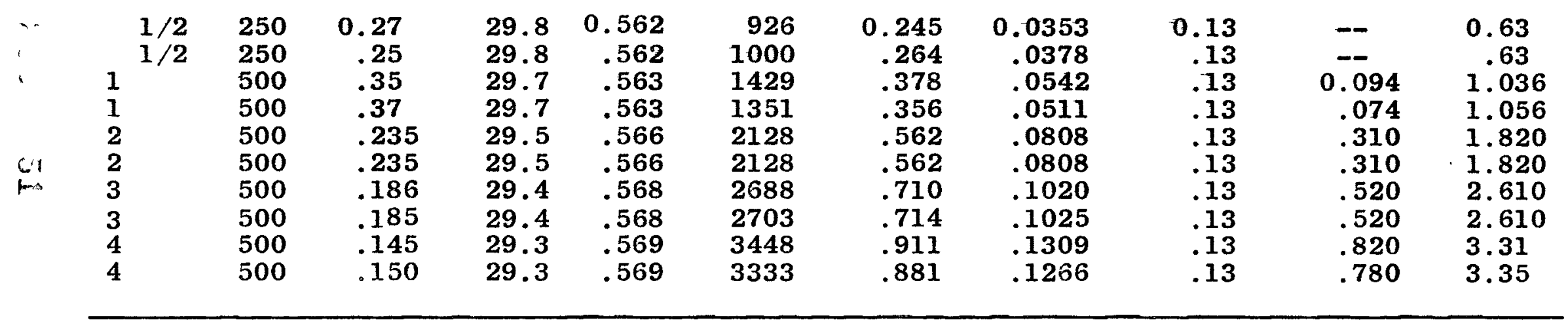


E. HAZE CHARACTERIZATION AND SETTLING RATE STUDIES

Prior to the start of filtration experiments, a little work was done on the subject of haze characterization and settling rates. This work consisted of nothing more than the manufacture of benzene-in-water and water-in-benzene dispersions by several procedures in an attempt to find the most satisfactory method of making hazes for test purposes. In order to obtain qualitative measurements on the dispersions which were made, the optical density was measured with a Lumetron Colorimeter, Model No.400, using no light filter. The manufacturer is the Photovolt Corporation, New York City. Two methods of making dispersions were tested. These were thermal methods and mechanical methods.

1.a A mixture of 1 liter of benzene and 1 liter of water was heated to about $65^{\circ} \mathrm{C}$, agitated, and then cooled rapidly to about $20^{\circ} \mathrm{C}$.

b Same as above, but cooling was slower and was only to about $30^{\circ} \mathrm{C}$.

c Mixture was agitated at room temperature and cooled rapidly to about $4^{\circ} \mathrm{C}$,

d Mixture was agitated at room temperature and cooled rapidly to about $20^{\circ} \mathrm{C}$.

2. Dispersion was made merely by vigorous mechanical agitation,

Table X shows a summary of the observations which were made on dispersions described above. 
TABLE X

Comparison of Various Hazes by Means of Light Absorption

\begin{tabular}{lccccc}
\hline $\begin{array}{l}\text { Method of } \\
\text { Preparation }\end{array}$ & $\begin{array}{c}\text { Rate of } \\
\text { cooling }\end{array}$ & $\begin{array}{c}\text { Initial } \\
\text { Temp. } \\
{ }^{\circ} \mathrm{C}\end{array}$ & $\begin{array}{c}\text { Final } \\
\text { Temp. } \\
{ }^{\circ} \mathrm{C}\end{array}$ & \multicolumn{2}{c}{$\begin{array}{c}\text { Optical Density } \\
\text { Wenter-in- Benzene-in- } \\
\text { Benzene }\end{array}$} \\
\hline (1a) Thermal & Rapid & 64.3 & 20.0 & 1.00 & 1.55 \\
(1b) Thermal & Slow & 63.1 & 32.3 & 0.85 & 0.65 \\
(1c) Thermal & Rapid & 33.2 & 2.8 & 0.30 & 0.30 \\
(1d) Thermal & Rapid & 33.2 & 20.0 & 0.68 & 0.20 \\
(2) Mechanical & - & 33.2 & 33.2 & 0.05 & 0.10 \\
\hline
\end{tabular}

On the basis that a high optical density is indicative of a large number of finely divided droplets, method (1a) appeared to produce the finest dispersion in both phases. Consequently, another batch of hazes was prepared by this method, and observations were made relative to the rate of settling of the dispersed phase. Data are listed in Table XI, and are shown graphically in Figure 17. 
TABLE XI

Measurement of Settling-Rates of Benzene-Water Dispersions

\begin{tabular}{|c|c|c|}
\hline \multirow{2}{*}{$\begin{array}{r}\text { Time after } \\
\text { Preparation } \\
\text { min. }\end{array}$} & \multicolumn{2}{|c|}{ Optical Density of Dispersion } \\
\hline & Water in Benzene & Benzene in Water \\
\hline 0 & 4.1 & 4.5 \\
\hline 5 & 3.8 & 4,0 \\
\hline 10 & 3.7 & 3.7 \\
\hline 15 & 3.3 & 3.6 \\
\hline 20 & 2.9 & 3.3 \\
\hline 25 & 2.8 & 3.2 \\
\hline 30 & 2.6 & 3.2 \\
\hline 190 & 1.55 & 0.90 \\
\hline 195 & 1.40 & 0.80 \\
\hline 200 & 1.35 & 0.55 \\
\hline 205 & 1.25 & 0.95 \\
\hline 210 & 1.25 & 0.85 \\
\hline 215 & 1.00 & 0.75 \\
\hline
\end{tabular}

These data for thermal methods indicated that, although the dispersions did settle, the rate was sufficiently slow to allow them to be used easily in the filtration tests. 


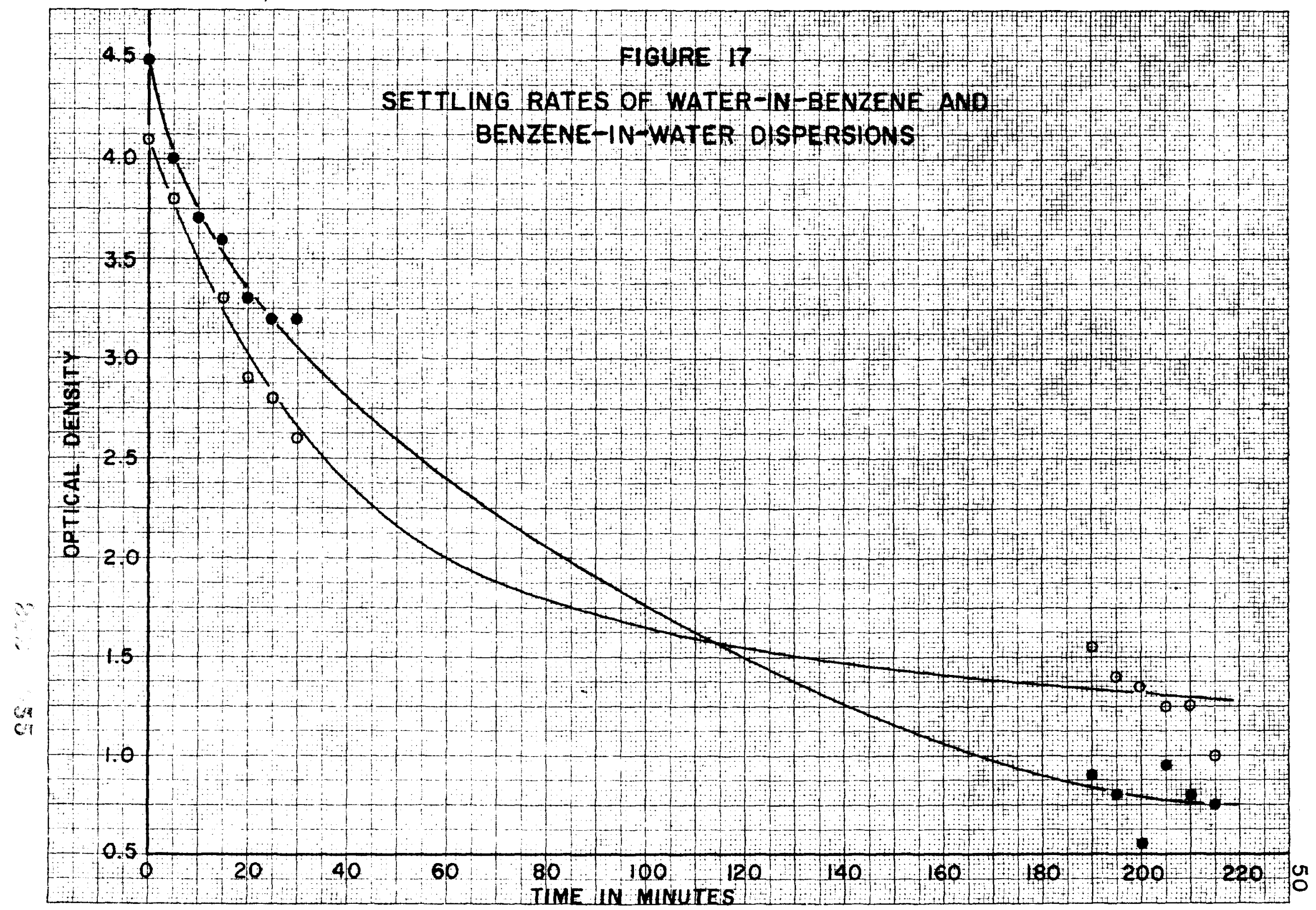


F. CLEANING PROCEDURE FOR TUBULAR FRITTED-GLASS FILTERS

The suggested procedure for cleaning fritted ware is to wash with hot hydrochloric acid and rinse with distilled water before use to remove any foreign matter such as dust. According to information from the manufacturer, many precipitates can be removed from the filters by washing thoroughly from the reverse side with distilled water. However, several chemical means are suggested. In the course of the work reported here, the filters were originally cleaned with hydrachloric acid, then subsequently cleaned when necessary in hot sulfuric acid plus a few crystals of potassium nitrite. This latter procedure was found to be quite satisfactory for the purposes at hand. 